\title{
Dating painting events through by-products of ochre processing: Borologa 1 Rockshelter, Kimberley, Australia
}

\author{
Bruno David ${ }^{a, b}$ (D), Jean-Jacques Delannoy ${ }^{b, c}$, Fiona Petchey,d, Robert Gunn ${ }^{\mathrm{a}}$, Jillian Huntley ${ }^{\mathrm{e}}$, \\ Peter Veth ${ }^{b, f}\left(\mathbb{D}\right.$, Kim Genuite $^{c}$, Robert J. Skelly ${ }^{\mathrm{a}}$, Jerome Mialanes ${ }^{\mathrm{a}, \mathrm{b}}$ (D), Sam Harper ${ }^{f}$, Sven Ouzman ${ }^{f}$, \\ Balanggarra Aboriginal Corporation ${ }^{g}$, Pauline Heaney ${ }^{h}$ and Vanessa Wong ${ }^{i}$

\begin{abstract}
${ }^{a}$ Monash Indigenous Studies Centre, Monash University, Clayton, Australia; ${ }^{b}$ Australian Research Council Centre of Excellence for Australian Biodiversity and Heritage; 'Laboratoire EDYTEM, Université Savoie Mont Blanc, Le Bourget du Lac Cedex, France;

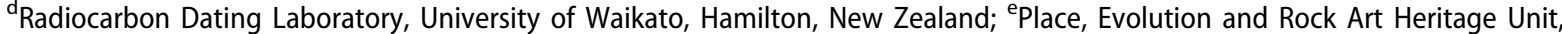
Griffith Centre for Social and Cultural Research, Griffith University, Gold Coast, Australia; ${ }^{f}$ Archaeology and the Centre for Rock Art Research + Management, M257, School of Social Sciences, Faculty of Arts, Business, Law and Education, The University of Western Australia, Crawley, Australia; ${ }^{9}$ Balanggarra Aboriginal Corporation, Wyndham, Australia; ${ }^{\mathrm{h}}$ Lettuce Create, Strathpine, Australia; 'School of Earth, Atmosphere and Environment, Monash University, Clayton, Australia
\end{abstract}

\begin{abstract}
The 'direct' dating of rock art has proliferated since the development of accelerator mass spectrometry radiocarbon, uranium-series and optically stimulated luminescence dating, yet still, most rock art is not directly datable due to the mineral nature of the constituent pigments. Here we present another method: the recovery and dating by stratigraphic association of small buried fragments of ochre and dried paint drops deposited onto soft sediment surfaces as by-products of paint production and use. These finds also give added contextual occupational information for archaeology of painting events. The case is made through the example of Borologa 1, a richly decorated Wanjina rockshelter in the Kimberley region of northwestern Australia that contains buried hearths, grindstones, earth pigments and small fallen spalls of rock containing traces of pigment and paint drops. Results from excavation indicate the beginning of Wanjina motifs and associated painting conventions on Art Panel B1 sometime between 2,080-1,160 cal BP and their proliferation in the past millennium.
\end{abstract}

ARTICLE HISTORY

Received 29 August 2018 Accepted 2 April 2019

\section{KEYWORDS}

Aboriginal sites; archaeological excavation methods; dating rock art; Kimberley; ochre processing; Wanjina

\section{Introduction}

The late 1980s and early 1990s saw a notable shift in the treatment of rock art by archaeologists worldwide. Advances in accelerator mass spectrometry (AMS) radiocarbon dating (capable of dating tiny samples measured in milligrams of carbon), uranium-series (U-series) and optically stimulated luminescence (OSL) dating of mineral accretions over or under rock art, and refined micro-geomorphological analyses of rock surfaces containing paintings and engravings, enabled improved absolute and relative chronologies which could situate rock art more reliably in conventional archaeological narratives of the past (e.g. Watchman 1987, 2000; Watchman et al. 2000). These innovations came concurrently with a renewed interest in symbolic expressions and cognitive archaeology (e.g. Chippindale and Taçon 1998). What has not been as methodologically forthcoming, however, are developments (and improvements) in the logic, planning and methods of excavation to understand better the antiquity of artistic activities within sites, and of artworks on rock surfaces (but see McNiven et al. 2009). Here we present excavation results from Borologa 1, a painted rockshelter in the Kimberley region of northwestern Australia, with an eye to studying the antiquity of iconic Wanjina-style rock paintings and their associated design conventions. We use 'Wanjina' rather than 'Wandjina' or 'Wondjina' as this is the term preferred by local Aboriginal communities in the East Kimberley, where this work was conducted (see also Akerman 2016). Our aim is to develop a new focus on the recovery of evidence relating to ochre processing and use as a means of clarifying the antiquity and activities of individual artistic events - an under-appreciated scale of analysis in archaeology.

\section{Wanjina}

The Kimberley region of northwest Australia contains thousands of rock art sites under overhangs,

CONTACT Bruno David bruno.david@monash.edu B Monash Indigenous Studies Centre, 20 Chancellors Walk, Monash University, Clayton Campus, Victoria 3800, Australia

(C) 2019 Australian Archaeological Association 
Table 1. Style sequence nomenclature.

\begin{tabular}{|c|c|c|c|c|c|}
\hline \multirow{2}{*}{$\begin{array}{l}\text { Proposed } \\
\text { sequence }\end{array}$} & \multicolumn{4}{|c|}{ Period } & \multirow[b]{2}{*}{ Summary characteristics } \\
\hline & Welch 1993 & Walsh 2000 & Donaldson 2012 & Veth et al. 2018 & \\
\hline \multirow[t]{8}{*}{ Earliest } & Archaic & Archaic & & & Pecked cupules and abraded grooves \\
\hline & & $\begin{array}{l}\text { Irregular } \\
\quad \text { Infill Animal }\end{array}$ & $\begin{array}{l}\text { Irregular } \\
\quad \text { Infill Animal }\end{array}$ & $\begin{array}{l}\text { Irregular } \\
\quad \text { Infill Animal }\end{array}$ & $\begin{array}{l}\text { Stencils, prints, large outline fauna and } \\
\text { anthropomorphs with stippled irregu- } \\
\text { lar infill }\end{array}$ \\
\hline & & Bradshaw Group & & & \\
\hline & Tasselled Figure & $\begin{array}{l}\text { Tasselled } \\
\text { Bradshaw }\end{array}$ & Ngunuru Gwion & Gwion (tassel) & $\begin{array}{l}\text { Graceful, finely painted, slim- } \\
\text { bodied anthropomorphs with tassel } \\
\text { ornamentation, elongated head- } \\
\text { dresses and sometimes holding boo- } \\
\text { merangs or wearing dillybags. Small } \\
\text { animals associated }\end{array}$ \\
\hline & Bent Knee Figure & Sash Bradshaw & Yowna Gwion & Gwion (sash) & $\begin{array}{l}\text { Elongated anthropomorphs with very } \\
\text { tall headdresses, sash-like aprons and } \\
\text { flexed knees (dancing?) }\end{array}$ \\
\hline & $\begin{array}{l}\text { Kimberley } \\
\text { Dynamic Figure }\end{array}$ & $\begin{array}{l}\text { Elegant } \\
\text { Action Figures }\end{array}$ & Dynamic Gwion & Gwion (dynamic) & $\begin{array}{l}\text { Elongated anthropomorphs with little } \\
\text { body ornamentation and mostly } \\
\text { depicted in active poses } \\
\text { (e.g. running) }\end{array}$ \\
\hline & Straight Part Figure & Clothes Peg Figure & Dalal Gwion & $\begin{array}{l}\text { Static } \\
\text { Polychrome } \\
\text { Figure }\end{array}$ & $\begin{array}{l}\text { Anthropomorphs in static frontal pose } \\
\text { and with conical headdresses. Often } \\
\text { bichrome (although the more fugi- } \\
\text { tive colours may be lost). Barbed } \\
\text { spears, hooked spear-throwers and } \\
\text { boomerangs present }\end{array}$ \\
\hline & Painted Hand & Clawed Hand & Painted Hands & Painted Hand & $\begin{array}{l}\text { Broad-brush outline paintings with seg- } \\
\text { mented or grid infill. Individual out- } \\
\text { lined hands with tapering fingers }\end{array}$ \\
\hline \multirow[t]{2}{*}{ Most recent } & Wanjina & Wanjina & Wanjina & Wanjina, Contact & $\begin{array}{l}\text { Monochrome and polychrome Wanjina } \\
\text { anthropomorphs (head, head+body, } \\
\text { or headdress alone) and animals }\end{array}$ \\
\hline & Contact & & Contact & & $\begin{array}{l}\text { Anthropomorphs and objects from the } \\
\text { European-contact period }\end{array}$ \\
\hline
\end{tabular}

on rockshelter walls, and engraved in the open. There are also related symbolic expressions such as stone arrangements, but we here restrict ourselves to rock paintings. A number of style sequences have been devised to order chronologically the rock paintings of the Kimberley (for a summary, see Table 1); we follow Veth et al. (2018) and note the problematics inherent in the word 'style', which are beyond the scope of this paper. One of the most iconic styles - Wanjina - consists mainly of human-like faces sometimes with partial or whole bodies, and often associated with the serpent ungud as well as with other motifs such as animals and plants. These motifs are often painted on prepared white pigment backgrounds. Wanjina rock art continued to be painted into the twentieth century and, in some areas, to the present day (see Morwood et al. 2010). While we know that Wanjina paintings occur across an area c. $600 \mathrm{~km}$ long (north-south) by c. $700 \mathrm{~km}$ wide (east-west) (for a map, see Akerman 2016), we do not yet know exactly when the style or its various painting conventions began, nor precisely how its commencement interphases with earlier styles. Understanding the antiquity of the style has considerable importance for understanding the foundations of historically documented Aboriginal world views relating to Wanjina imagery.
Any discussion of human occupation and symbolic inscription of Kimberley cultural landscapes must accord primacy to local Aboriginal conceptions of the Dreaming (called lalai and lalan in the northwest and central Kimberley, respectively) and ongoing connections to land and cynosuric places (focal places of signification) (e.g. Balanggarra Aboriginal Corporation and Kimberley Land Council 2011). In a recent volume on the northwest Kimberley, Blundell et al. (2017:44) noted the ubiquitous presence of Wanjina with whom people constantly interact: 'The country is perceived as the embodied consequence of the actions of powerful ancestral creator beings rather than as a landscape that has been altered through the actions of geological or climatic events, or by human agents'. In a very real sense, rock art is understood to be a product of both ancestral and contemporary actions that include the ritual attendance (including through painting and repainting) of ancestral beings called Wanjina.

Wanjina are found exclusively in the Kimberley, mainly on rock surfaces across Worrora, Ngaranyin, Wunambal and Balanggarra lands. Historical and other accounts connect individual Wanjina paintings with the locations where the ancestral Wanjina spirit-beings lay down in the Dreaming (for ethnographic and recent textual accounts of Wanjina, see Capell 1972; Crawford 
1968; Elkin 1930; Lommel 1952; Mowaljarlai and Malnic 1993; Schulz 1956; see also Akerman 2016; O'Connor et al. 2008). Repainting of Wanjina imagery is a ritual action undertaken by initiated Aboriginal men of the appropriate affiliation to Country and as mediators of the Wanjina themselves (Blundell et al. 2017:70). These are formal activities that ensure the regeneration of the landscape's fertility and life processes (Blundell et al. 2017:70; see also Veth et al. 2018). The knowledge and connections to the power associated with the Wanjina and the life forces they emit make the act of repainting sacred (Crawford 1968).

Wanjina originated either from the sky or sea, and travelled, fought and created as they journeyed, metamorphosising onto the rock as paintings imbued with affective life-forces. They control fertility, growth, landscape processes, and provide instruction on social behaviour and how to look after Country ('Law'), including the rules relating to appropriate marriage partners, the location of clan estates and the undertaking of rituals. People can communicate with Wanjina through dreams and can be given songs and dances as well as advice on matters such as painting and repainting. Wanjina rock images are clearly not just paintings in local Aboriginal ontologies but are themselves sentient beings (e.g. Blundell et al. 2017).

\section{How old is the Wanjina style of painting?}

Over the past three decades, radiocarbon and luminescence dating have been applied to determine the age of Wanjina paintings (e.g. Morwood et al. 2010; Roberts et al. 1997; Ross et al. 2016). The customary repainting of Wanjina on rock surfaces means that for each motif there will probably be a sequence of painting events, from first iteration through to the most recent additions. Morwood et al. (2010) obtained a radiocarbon age of $3,780 \pm 60 \mathrm{BP}$ (calibrated at $95.4 \%$ probability to $4404-3981 \mathrm{cal} \mathrm{BP}$ ) on beeswax that made up a Wanjina head motif, giving a minimum age for the start of Wanjina motifs as an image type. More recent radiocarbon ages were also obtained on other Wanjina head motifs and on fauna painted in the Wanjina style, indicating the continuity of painting events into the colonial period: 'heavily repainted examples only date to the last $375 \pm 35$ years - the age of the lowermost of thirty-eight layers of paint in a Wandjina-style snake depiction' (Morwood et al. 2010:6; see also Watchman 1987).

Roberts et al. (1997) applied luminescence dating to fossilised mud-dauber wasp (Sceliphron laetum) nests overlying rock art, including an 'early phase'
Wanjina head from Borologa 1 (also known as Wandjina Rock) along the Drysdale River. Three wasp nests (DR1, DR2 and DR6) were dated from Borologa 1, the one on the Wanjina head (DR6) being sampled sequentially down the height of the nest to test for modern, contaminating sunlight exposure. Two generations of nest building dating to $110 \pm 20$ and $610 \pm 50$ years ago were determined from the OSL ages on DR6. Because the nest was built over the Wanjina painting, the painting itself must be at least c. 600 years old. The other two nests (DR1 and DR2) both date to the past 100-150 years (see also Aubert 2012).

The oldest age published for a purported Wanjina-style motif is a minimum OSL age of $5,100 \pm 240$ years for a mud-dauber wasp nest overlying a striped macropod painting (Ross et al. 2016, sample LM-13). The motif is a kangaroo with body and limbs divided into sections with the entire motif infilled with fine longitudinal lines, and the addition of white dotting on the shoulders, forearms and kidneys. Ross et al. (2016:13) suggested that the backbone and kidneys are similar to X-ray art of Arnhem Land to the east, which has a dated beginning from the midHolocene. Ross et al. (2016:26) argued that 'simple $\mathrm{X}$-ray elements have been recorded in three Gwion Period figures ... but are more common in the Painted Hand Period motifs where animals are sometimes depicted with backbone and ribs'. This is of interest as it suggests that the X-ray design found in the LM-13 motif may be an early, transitional convention that pre-dates the Wanjina style itself.

On the current ages available, the 'proliferation phase' for classic Wanjina iconography dates to the past millennium (Morwood et al. 2010). While some earlier design elements that overlap with those of Wanjina style motifs may be several thousand years older, the age of the beginning of most design elements remains unknown.

\section{Borologa 1}

Borologa 1 is a $7 \mathrm{~m}$ high rock stack at the base of a steep hill on the banks of the Drysdale River. Although Balanggarra Elders of the late 1980s and early 1990s identified the site as 'Borologa' (as recorded by rock art enthusiast Joc Schmiechen, see Welch 2015:69), it has been popularly known by visitors to the Drysdale River National Park as 'Wandjina Rock', after its many Wanjina paintings. During the early dry season when flood waters have abated, the site is located $120 \mathrm{~m}$ north of the Drysdale River in the northern Kimberley region (Figures 1 and 2). The rock stack consists of 

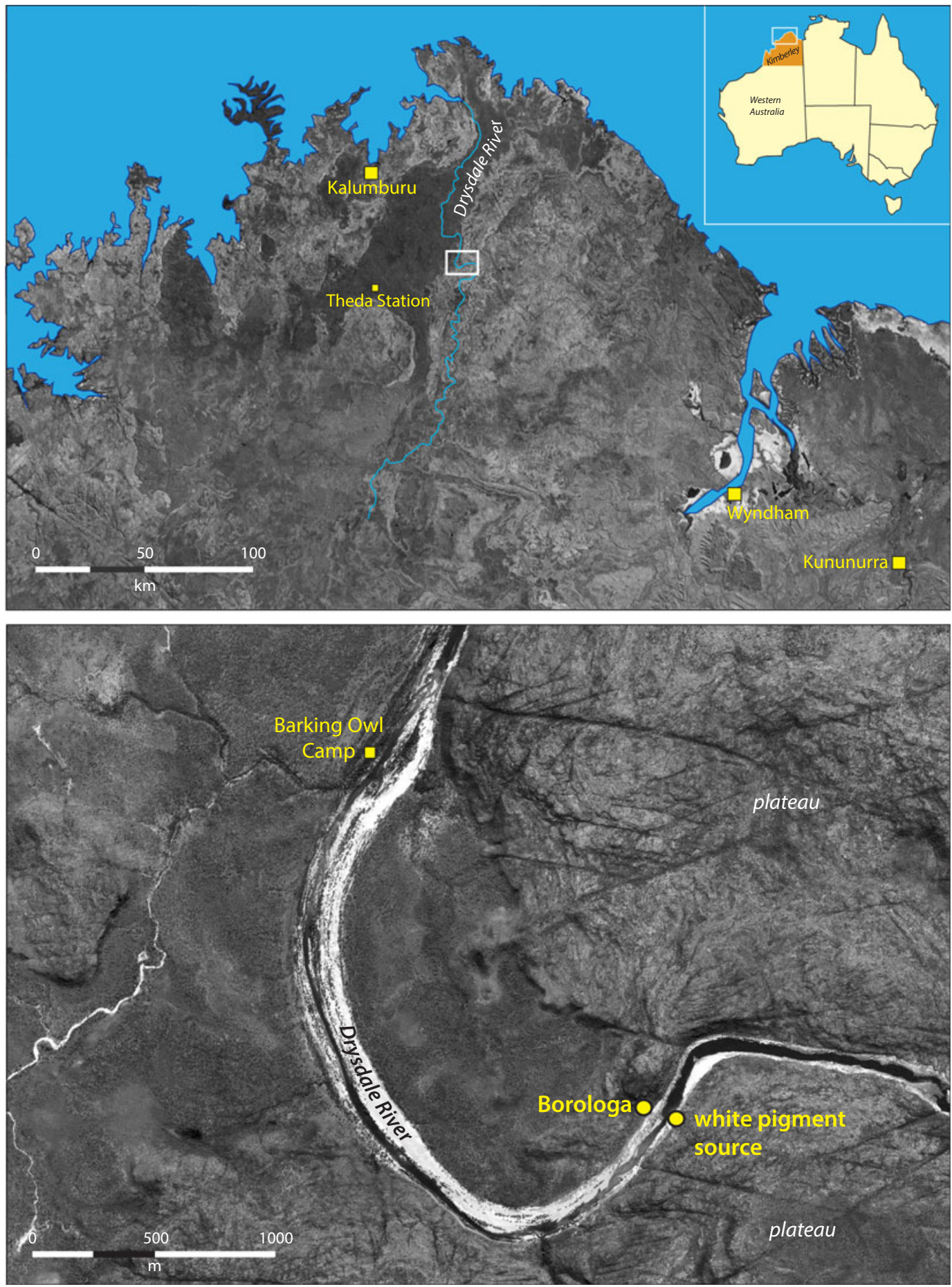

Figure 1. Location of Borologa 1, northwestern Australia (photos: Jean-Jacques Delannoy).

south-southwest-tilted quartzite and sandstone layers (designated rock strata D3-D25) sitting on a subhorizontal bedrock pedestal also comprised of superimposed hard quartzite layers (strata D0-D2), with rock stratum D0 only partially exposed above ground (see Figure 3 for a visual representation of the rock strata that make up the stack). Two alcoves at ground level were created by a combination of geological weathering (rock fall) and human removal of rock strata (the evi- dence for human modification of the rock will be published elsewhere), resulting in sheltered areas under moderate overhangs with extensive evidence of bedrock flaking by people, production of rock art, and surface and buried cultural deposits (Figure 3). The soft sediments fronting the south side of the site consist of aeolian sands over an ancient alluvial terrace. Today the floor level lies $7 \mathrm{~m}$ above the seasonal high flood level of the Drysdale River. 

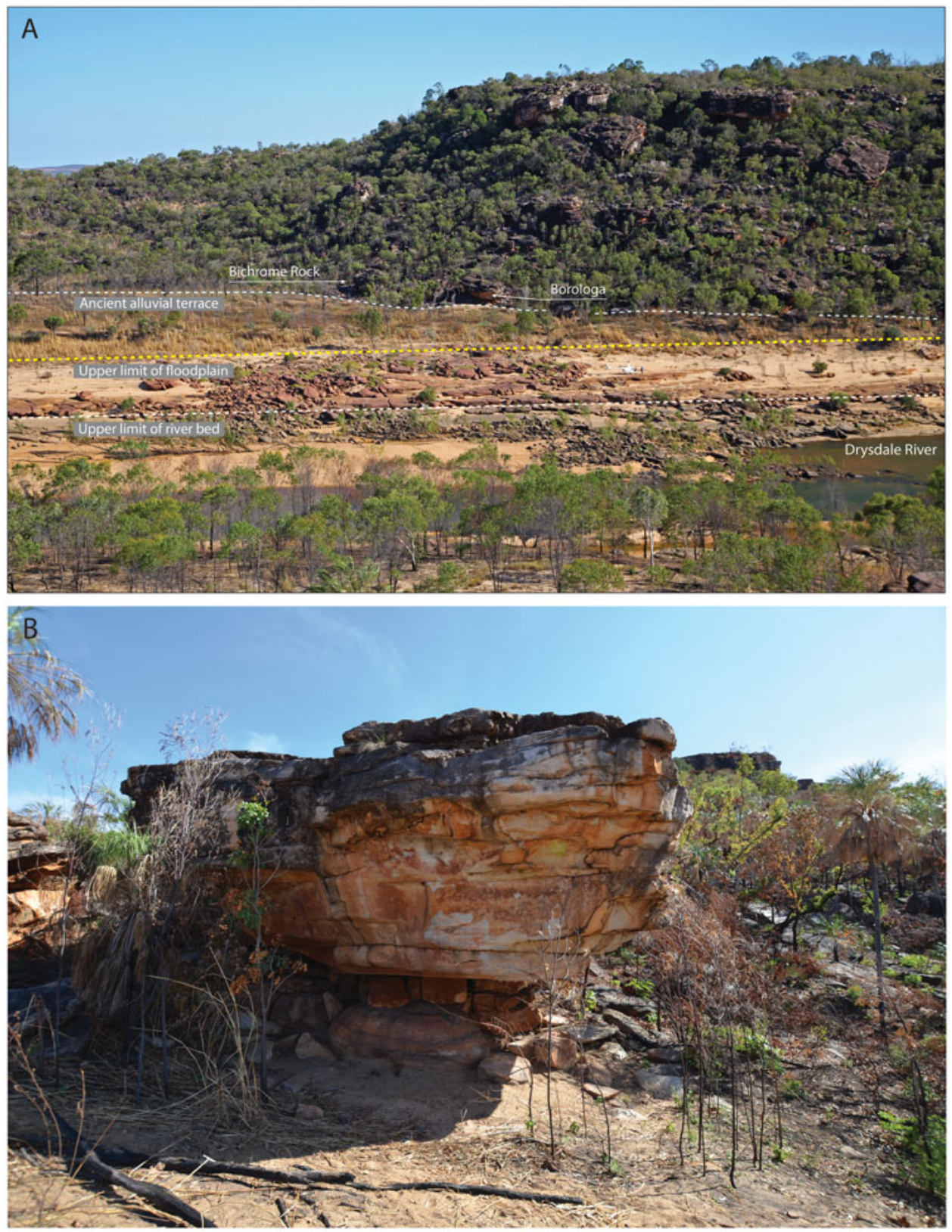

Figure 2. (A) Borologa 1 in its local setting. (B) Borologa 1 (photos: Jean-Jacques Delannoy).

\section{The rock art of Borologa 1}

\section{Methods}

We began by recording the rock art of Borologa 1 through detailed photography, drawings and notetaking, followed by digitally enhancing the photos to clarify painting conventions and determining patterns of superimposition. Individual paintings were attributed to established Kimberley rock art styles, as determined from the literature (see below). However, until more chronological details are forthcoming, we do not assume an inviolate unilinear temporal sequence for the style phases or sets of graphic conventions, nor do we exclude the possibility of additional 'styles'.

\section{Results}

Borologa 1 is extensively decorated with rock art, most prominently a ceiling panel featuring Wanjina motifs sheltered under a well-protected alcove in the southeastern side of the site (Art Panel B1, see Figure 3). Small grinding patches are found on horizontal rock surfaces in front of all the art panels. Those grinding patches are sometimes on movable rocks, sometimes on the outcropping flat bedrock, either at ground level or slightly more elevated. Grinding patches on the upper surfaces of two boulders in the alcove that houses Art Panel B1 bear traces of red pigment. Other shallow grinding patches are positioned near painted rock art panels (Figure 4) around the stack, suggesting that ochre 

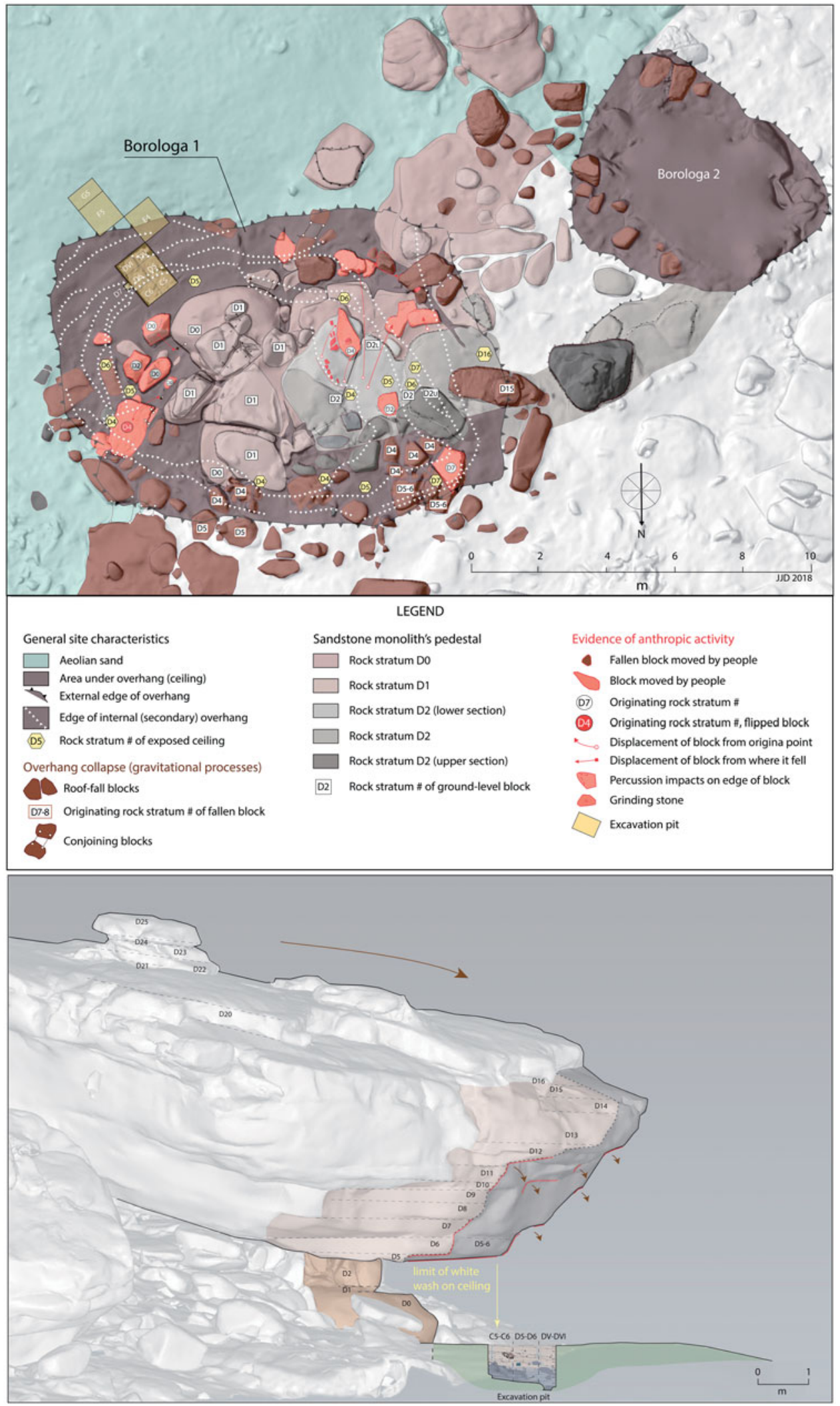

Figure 3. Plan (top) and side view (bottom) of Borologa 1 showing the monolith's rock strata and location of excavation squares (artwork: Jean-Jacques Delannoy).

was typically processed on rock palettes close to where the resulting paint would be used.

The rock art is found in 40 distinct art panels that together cover much of Borologa 1's western, southern and eastern sides (the rough, weathered rock on the northern side is exposed to the elements and shows no sign of artworks) (Figure 3). The art panels are found along $26 \mathrm{~m}$ of rock surface, spanning a height of some $2 \mathrm{~m}$ from just above the present ground level, the combined art 

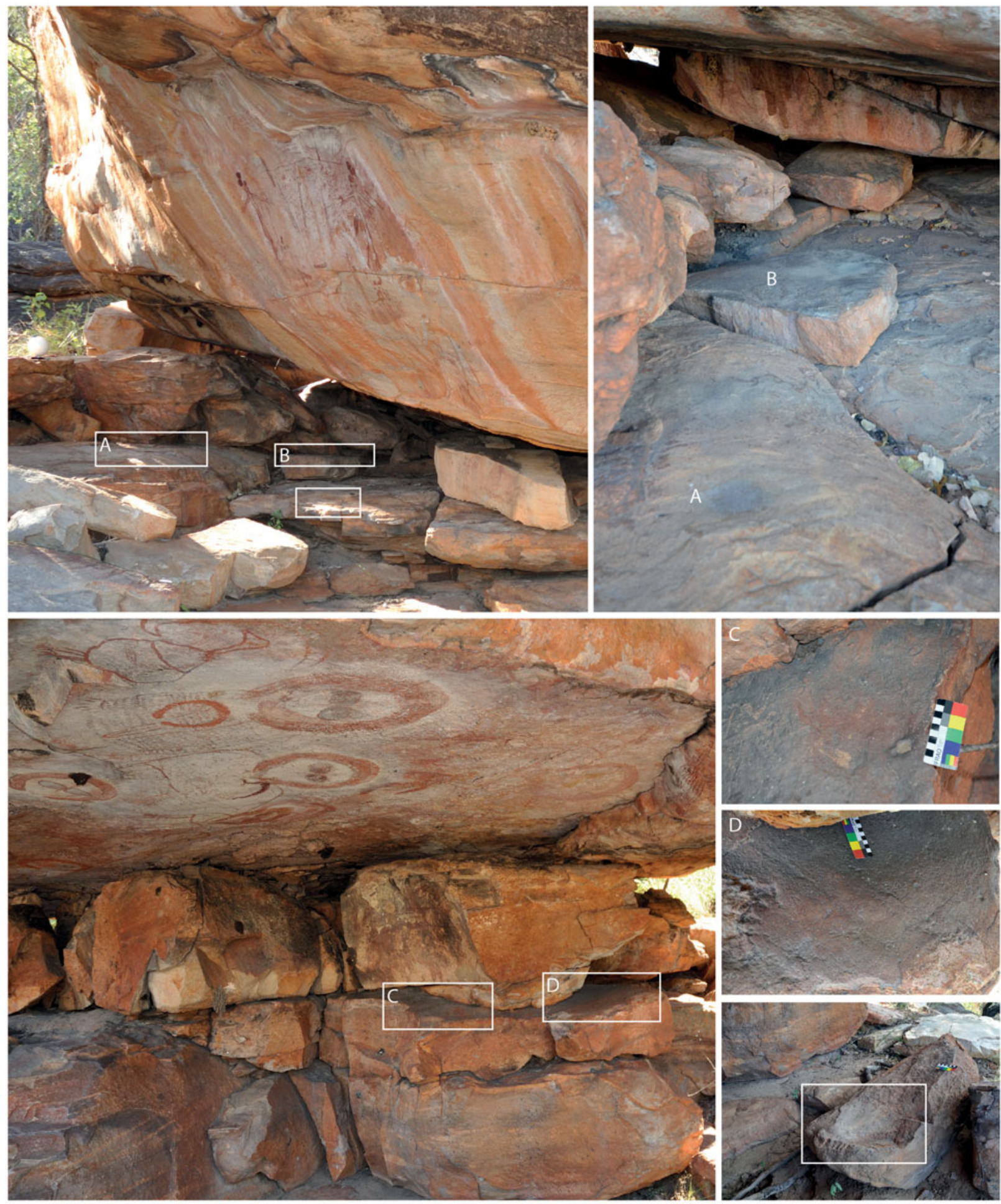

Figure 4. Grinding patches on rock surfaces near rock art panels, Borologa 1 (photos: Robert Gunn, Leigh Douglas and Bruno David).

area totalling $50.4 \mathrm{~m}^{2}$. A preliminary count recorded 446 motifs in a wide range of styles, colours, and states of preservation. Following the most recently established Kimberley style categories (after Donaldson 2012; Ouzman et al. 2017; Veth et al. 2018; Walsh 2000) (see Table 1), rock art from the early Irregular Infill Animal, Tasselled Gwion, Dynamic Gwion, and Static Polychrome Figure styles, and the more recent Painted Hand and Wanjina styles is present (Figure 5). Hand stencils, hand-prints and feather prints are also present. A number of distinctive stout anthropomorphic figures with vertical stripe infill also occur on several panels. Welch (2015) considered them to date probably to the earlier or later stages of the Painted Hand style, as they have characteristics of both bracketing styles (Static Polychrome Figure and Wanjina styles, respectively) (David Welch, pers. comm. 2018). Similarly, a distinct composition of 31 motifs, involving a type of 


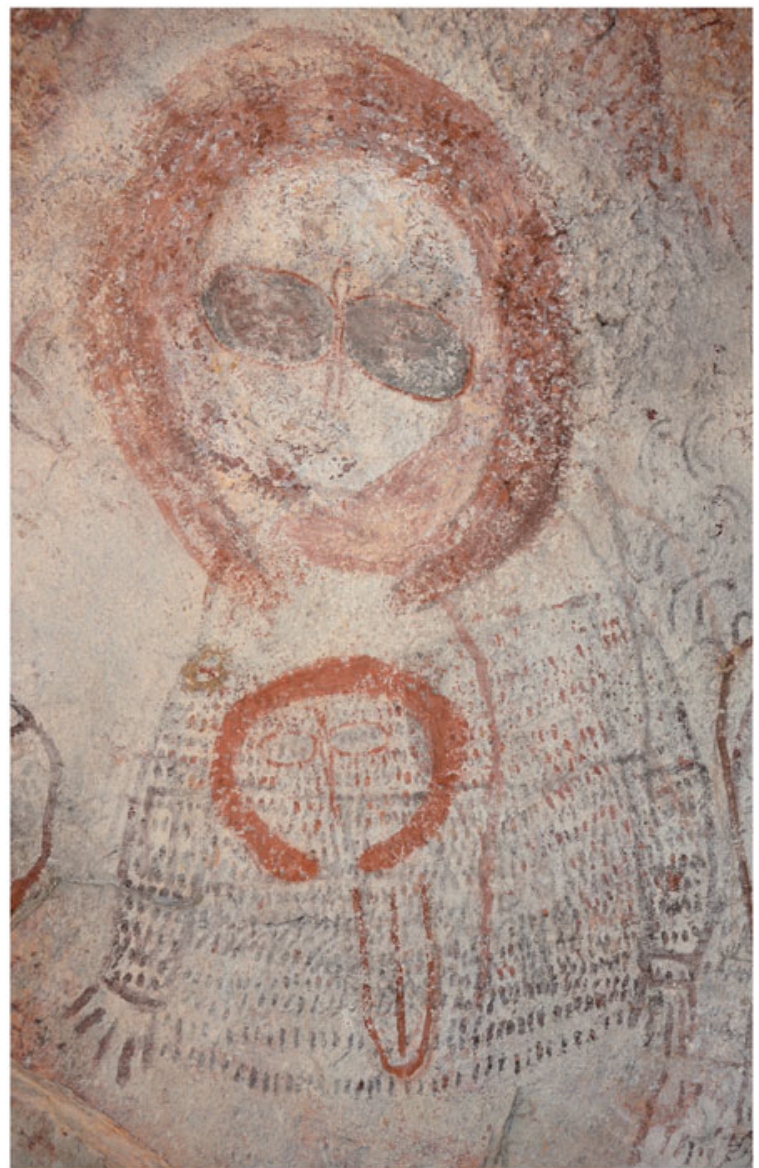

Figure 5. The apparently most recent Wanjina face on Art Panel B1 in bright red over an earlier head and upper body Wanjina (photo: Robert Gunn).

unclassified stick figure, is most likely from the Static Polychrome Figure style. Borologa 1 also contains a number of other motifs that cannot be allocated to particular styles. It is important to note that while the relative chronology of some of these style phases is undisputed - especially Gwion always preceding Wanjina paintings - the absolute antiquity and degree of overlap between many styles remains uncertain, as does the chronological position of a number of individual motifs (e.g. hand stencils and hand prints) in the broader schema.

At Borologa 1, only one Gwion style is represented on any given art panel, although paintings from different styles may occur on adjacent panels. Panels with Gwion figures may also contain Painted Hand style animal or Wanjina motifs. The Gwion motifs with tassel waist bands only occur on panels at the eastern end of the rock stack, whereas Dynamic Gwion and Static Polychrome Figures are restricted to those on the west. Art Panel E4, the largest vertical art panel on the western side, contains 13 Static Polychrome Figures in a range of colours, forms, associated artefacts and states of preservation. The Static Polychrome Figures are painted in monochrome red or yellow, or bichrome red and yellow, while the Tasselled Gwion and Dynamic Gwion occur only in monochrome red to mulberry. Most of the stout striped figures are in monochrome red (the exceptions being yellow or yellow and red) and occur on panels around the three decorated faces of the boulder, showing no preference for association with Gwion or Wanjina images.

Most of the Gwion figures are weathered and incomplete, but most appear to be between $10 \mathrm{~cm}$ and $50 \mathrm{~cm}$ tall based on comparisons with complete figures at other sites. There is little variation in height between the different types of Gwion figures. The stout striped figures are of similar size to the Gwion, whereas the two Painted Hand motifs are larger, being $71 \mathrm{~cm}$ and $165 \mathrm{~cm}$ long respectively. The Wanjina vary considerably in size, from $18 \mathrm{~cm}$ to $119 \mathrm{~cm}$, the variation largely due to whether a head or head and torso is depicted, and also to the size of the art panel on which it is placed as they are proportioned to fill the panel.

The Wanjina, whether represented by a singular head, upper body, or simply by an arc headdress, occur both in red monochrome and in polychrome (a white base decorated with red and/or black, yellow or cream). No Wanjina is represented with a complete body at Borologa 1, although such fullbodied examples are known from elsewhere in the Kimberley, the closest being c. $40 \mathrm{~km}$ to the south and to the west.

\section{Art Panel B1}

Art Panel B1 is located on the ceiling of the southeastern alcove (Figure 6), adjacent to the excavation squares reported below. The art consists of 107 paintings, two dry pigment drawings and two hand stencils. Art Panel B1 is the most densely decorated panel at the site, and is dominated by large and impressive Wanjina paintings, some with associated Wanjina-style animals. The Wanjina, whether as singular head or as head and upper body, occur both in monochrome red and polychrome (up to four colours). Polychrome Wanjina are limited to the large ceiling of the eastern alcove, while monochrome Wanjina occur both on this ceiling panel and on other, smaller, vertical wall panels on the eastern and southern sides of the site. No Wanjina occur on art panels on the western side of the site where Static Polychrome Figure motifs predominate.

Some of the polychrome Wanjina are painted on a white background, others not. All bar one of the polychrome Wanjina-with-torso show evidence of over-painting in the form of another Wanjina superimposed over an earlier one. These superimposed Wanjina have the same orientation as the 


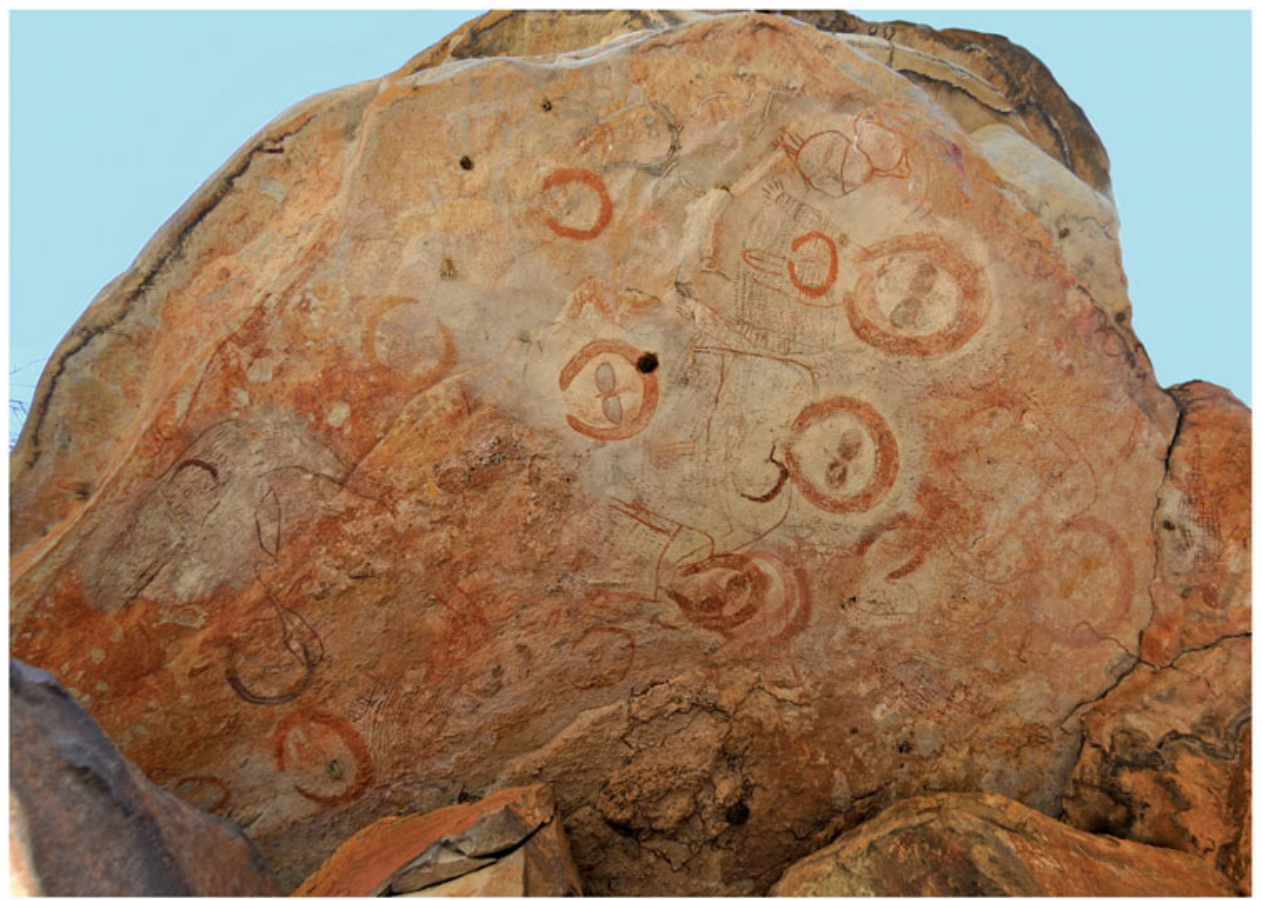

Figure 6. Photomosaic of Art Panel B1; the ceiling of the eastern alcove (photo: Robert Gunn).

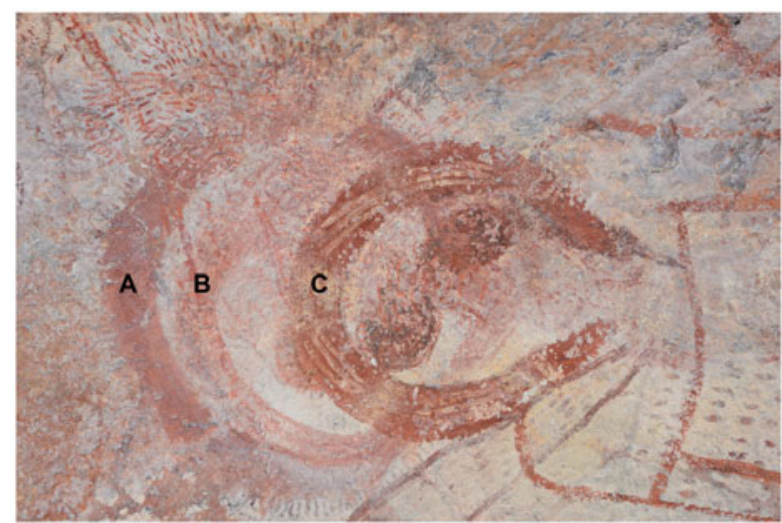

Figure 7. Three superimposed Wanjina figures $(A-C)$ on Art Panel B1 (photo: Robert Gunn).

underlying ones but are slightly offset. One sequence shows at least three superimposed Wanjina (Figure 7). Superimposition with nonWanjina art is, however, more extensive, with at least eight layers being deciphered from Art Panel B1 (Table 2); Art Panel E4 on the western wall of the boulder exhibits five instances of superimposition, and further examples are evident on other art panels at the site.

Art Panel B1 sits just above the northwestern edge of the excavation squares reported here (see Figure 8). A large part of the eastern half of the ceiling was painted in white to form a background for Wanjina figures, while other Wanjina images further to the west on Art Panel B1 do not have a pigment background. The white background was repainted at least once and is the only area of the site with
Table 2. Superimposition layers from the area of Art Panel B1 shown in Figure 5.

\begin{tabular}{ll}
\hline Relative chronology & \multicolumn{1}{c}{ Art layer characteristics } \\
\hline Most recent layer & $\begin{array}{c}\text { Area of bright red dashes } \\
\text { Wanjina with black centred eyes, red nose, and } \\
\text { yellow striped red headdress } \\
\text { Remnant of an outlined figure in red with legs } \\
\text { together, splayed feet, and short toes } \\
\text { Remnant of a dashed infill design fragment } \\
\text { in red } \\
\text { Wanjina with white face, red eyes and plain } \\
\text { band headdress } \\
\text { Wanjina with white face and short-rayed } \\
\text { band headdress } \\
\text { White solid area (background to Wanjina) } \\
\text { Outlined dumbbell shape in black (or discol- } \\
\text { oured red) }\end{array}$ \\
\hline
\end{tabular}

evidence for such a large quantity of white pigment being employed. The earlier white background, however, overlies another Wanjina figure that lacks a white background (Figure 9), indicating that the use of the white background for Wanjina figures does not signal the earliest depiction of Wanjina at this site. Based on patterns of superimposition, these Wanjina are among the most recent images on this panel. The most recent image of all appears to be a small monochrome Wanjina head positioned over the torso of an earlier polychrome Wanjina (Figure 5).

The earliest painting on Art Panel B1 is an outlined and internally decorated snake-like image on the outer edge of the panel (Figure 10). This image conforms to the style of the Painted Hand style. All of these images are from the latest styles in the known rock art of the Kimberley (Table 1). 


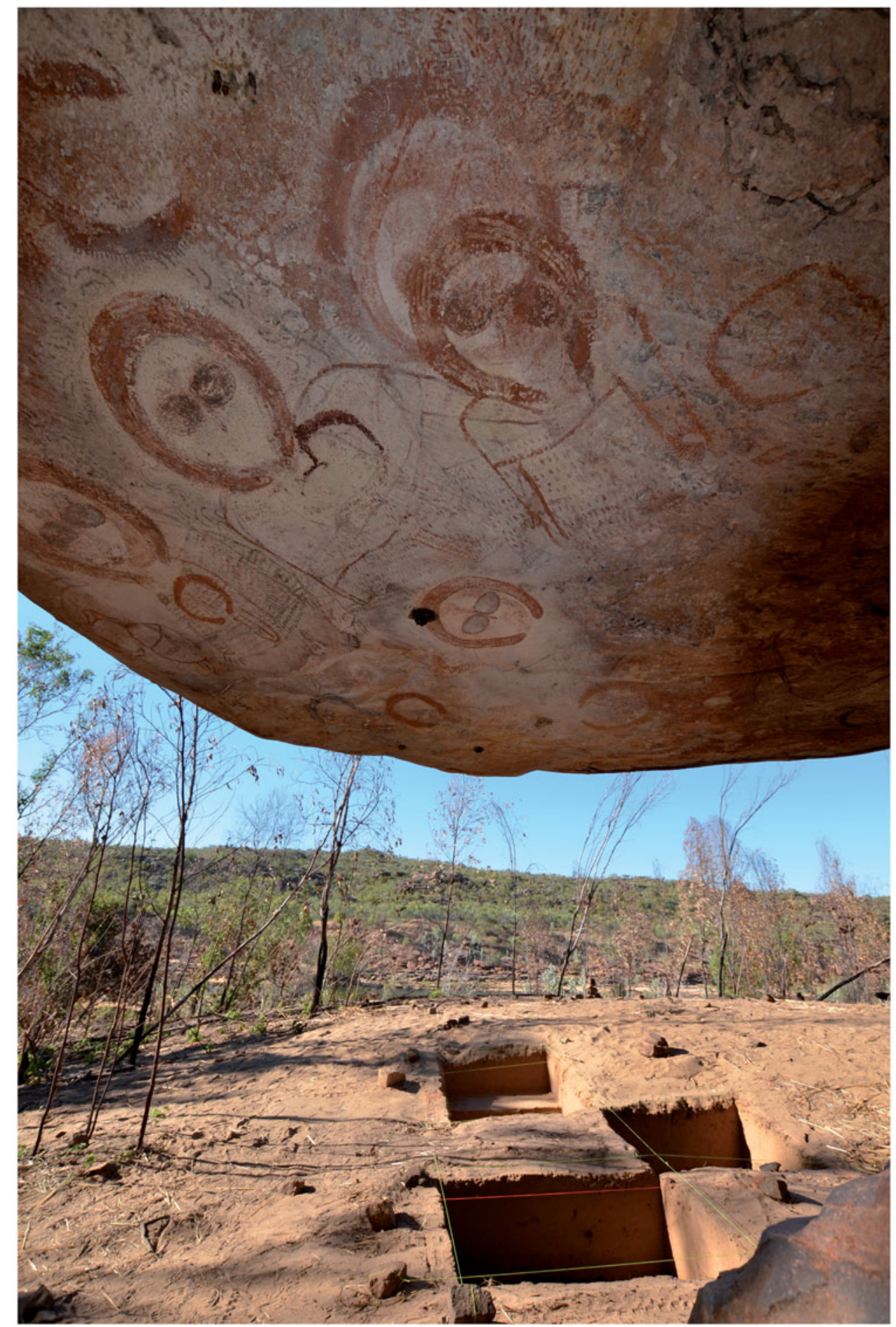

Figure 8. Excavation pits relative to Art Panel B1, excavations in progress, with Squares C5 and C6 (those closest to the Wanjina ceiling) not yet begun. The excavations reported in this paper concern the front pit. Pits E4 and F5-G5 are shown on the edge of and outside the dripline at rear of photo (photo: Bruno David).

\section{The excavation}

\section{Methods}

Three pits were excavated, all fronting Art Panel B1, the eastern alcove ceiling densely decorated with Wanjina paintings. Here we restrict our discussion to the pit closest to the art panel. The $1.2 \mathrm{~m}$ wide by $1.6 \mathrm{~m}$ long pit consists of four $60 \times 60 \mathrm{~cm}$ squares: C5, C6, D5 and D6; and two smaller $60 \times 40 \mathrm{~cm}$ squares: DV and DVI. In addition, a $20 \times 20 \mathrm{~cm}$ square (Square D7) was excavated against the northeastern wall of Square D6 after completion of the other six excavations (Figures 8 and 11). Square D7 was dug to compensate for the loss of much of the excavated material from Squares C5 and C6 in a helicopter mishap late in the final field season. 
Each Square was typically excavated in $1-2 \mathrm{~cm}$ thick arbitrary excavation units (XUs) following the stratigraphy of cultural layers (stratigraphic units SU1-SU5). However, XUs were often 3-4 cm thick in the more rocky, underlying culturally

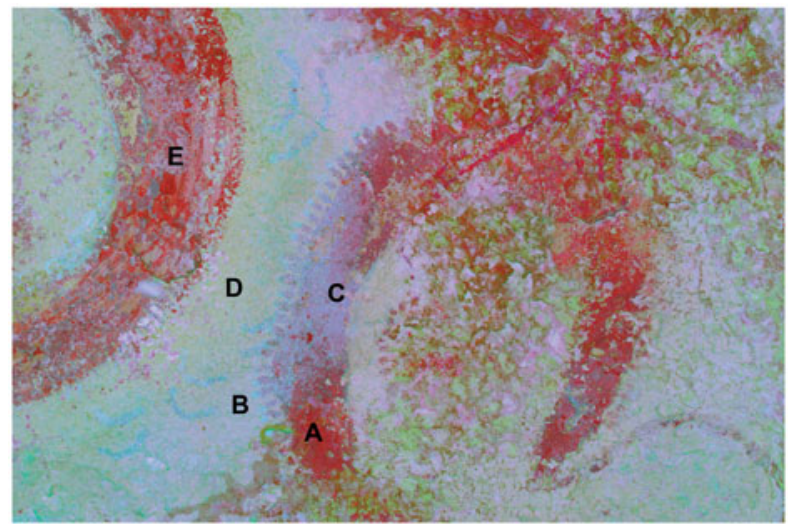

Figure 9. Earlier Wanjina figure (A) overpainted by white area background (B) at point (C). The pale green colour at (D) is a later white repainting over area (B), while (E) is part of the more recent Wanjina figure painted on to background (D) (enhancement in DStretch_ywe10) (photo and enhancement: Robert Gunn). sterile horizons (SU6-SU7). Artefacts $\geq 2 \mathrm{~cm}$-long, and selected smaller items including charcoal, were individually collected and plotted onto the $\mathrm{XU}$ recording forms (Table 3). The excavated sediments from the main pit were sieved in the field in $2 \mathrm{~mm}$-mesh, with all retained materials subsequently sorted at the Monash University archaeology laboratories. The Square D7 deposits were bulk-bagged by XU in the field, then sieved and sorted in the laboratory. Small, bulk sediment samples from each XU of each square were kept for sediment analyses. The lower levels of each square reached culturally sterile, impenetrable massive roof-fall rock in SU6 or SU7. It is not known whether further cultural layers lie beneath.

\section{Results}

\section{Stratigraphy and radiocarbon dating}

Table 4 describes the seven SUs identified in the excavation (Figures 12 and 13). Thirty-eight AMS radiocarbon ages were obtained on individual
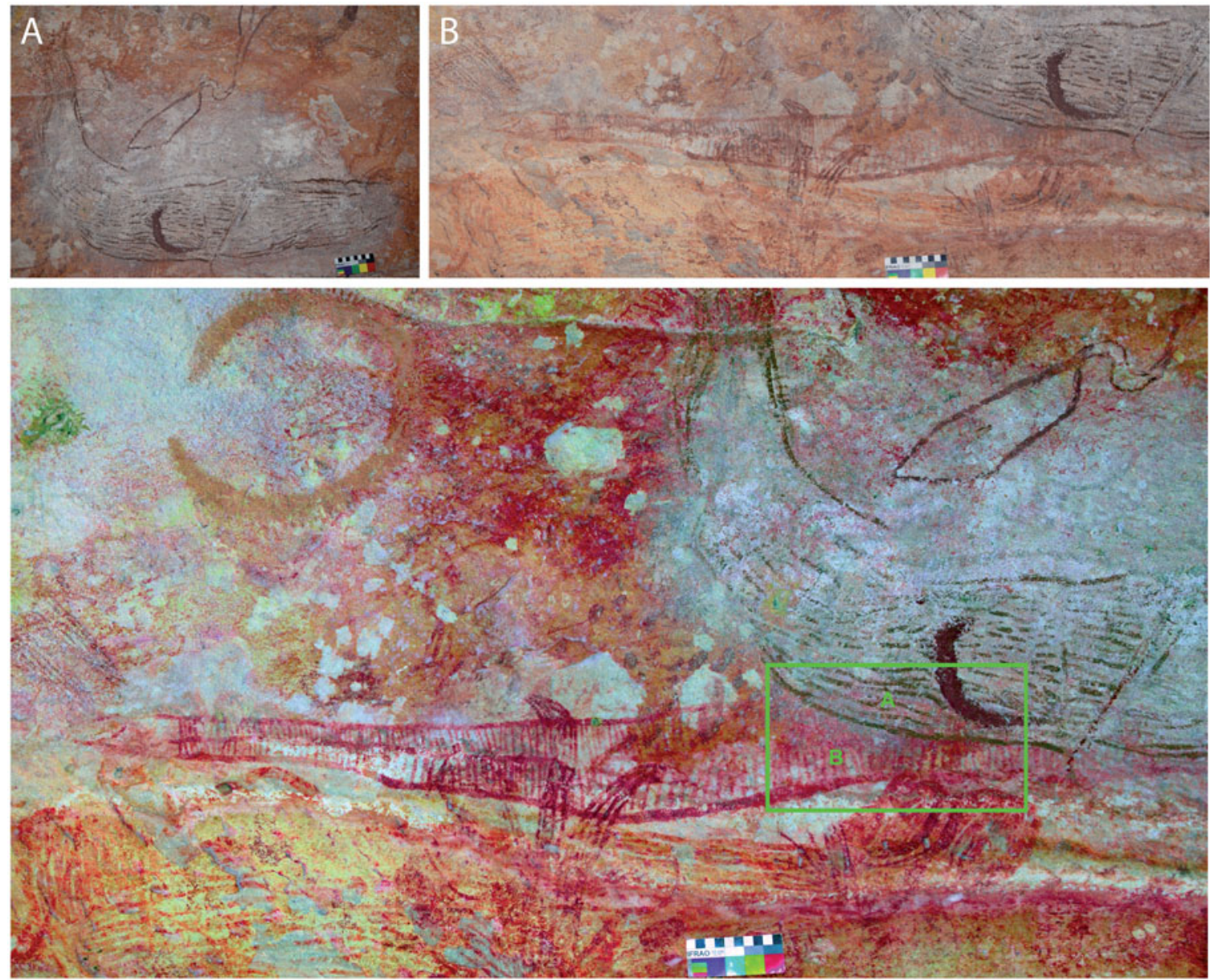

Figure 10. Parts of Art Panel B1. (A) Motif with outline, form and aspects of infill in some respects consistent with early Wanjina, but also sharing attributes of the Irregular Infill Animal style, overlying (B) an internally decorated snake-like image that conforms to the style of the Painted Hand style (the lower photo is enhanced with DStretch_Ird10). The apparent inversion of some stylistic conventions highlights one of the problems with the currently proposed stylistic sequences for Kimberley rock art (photos and enhancement: Robert Gunn). 


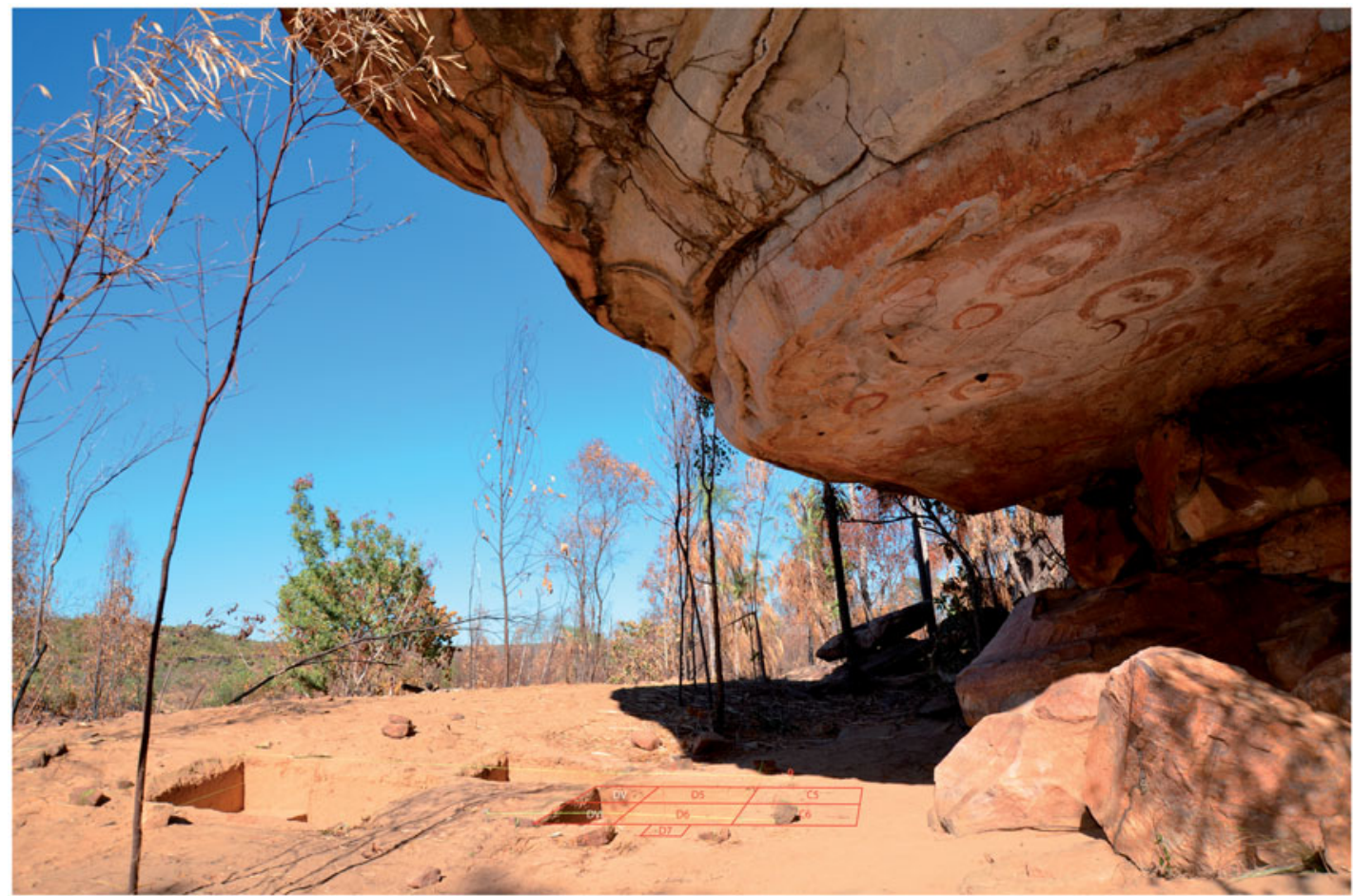

Figure 11. Borologa 1, showing location of excavation squares relative to Art Panel B1 (photo: Bruno David).

pieces of charcoal. Twenty-nine were recorded in situ during excavation, the other nine came from the sieves (Table 5). To determine the age of onset, end and duration of each phase of sediment deposition, we have used OxCal v4.3 (Bronk Ramsey 2018) to develop a Bayesian Sequence Analysis whereby radiocarbon ages are constrained by the stratigraphic structure of the deposit (Bronk Ramsey 2009). We note that neither the unmodelled ages nor the Bayesian Sequence Analysis takes into account potential inbuilt ages in the wood charcoal (e.g. Allen \& Wallace 2007; Schiffer 1987), which in this environment could be up to a few decades old, or more if the wood is cypress pine (Callitris intratropica). Wk-44512 at the base of SU1B was manually rejected prior to Bayesian Sequence Analysis as it contains bomb carbon indicating a modern (post$A D$ 1950) age. It is the only radiocarbon age with a post-bomb result and is associated with nearsurface charcoal from a recent bushfire. The remaining samples were grouped into seven chronostratigraphic Phases, from top to bottom (Figure 15):

- Base of SU1B (includes SU1B-SU2 interface): $450-120$ to $270-190$ cal BP. This Phase relates to when the very top of SU2 was the ground surface.

- SU2: $480-340$ to $450-120$ cal BP.

- SU3 hearth layer (includes SU3-SU4 interface): $630-500$ to $480-340$ cal BP. It includes a number of stratigraphically inter-connected hearths and a plant-processing basal grindstone and topstone.

- Base of SU4 (includes SU4-SU5 interface), when the very top of SU5 was the ground surface: $1,110-970$ to $910-760$ cal BP.

- SU5: This consists of the bulk of the SU5 deposit, stratigraphically above the lower two Phases listed below: 2,080-1,610 to $1,600-1,160 \mathrm{cal} \mathrm{BP}$.

- Base of SU5 (includes SU5-SU6 interface), when the fallen rock at the top of SU6 was the ground surface: $2,370-2,180$ to $2,320-2,110 \mathrm{cal} \mathrm{BP}$.

- Hearth at base of SU5: 3,000-2,500 to 2,690-2,270 cal BP. This small hearth is located on the rock surface at the junction of Squares C5, C6, D5 and D6, at the very base of SU5.

The earliest five Phases were separated by uniform, sequential age boundaries representing the age hiatus identified between events. The base of SU1B, SU2 and the SU3 hearth layer Phases are chronostratigraphically differentiated and were therefore separated by contiguous age boundaries in the model (see Bronk Ramsey 2009). We tested the internal consistency of the calibrated ages using an outlier detection method that enables a probabilistic measure of the degree to which samples appear to be outliers and then calculates an offset relative to the broader chronostratigraphic context within which it is found (Bronk Ramsey et al. 2010). In this instance, a General t-type Outlier Model was inset into the Bayesian Sequence Analysis and all ages were assigned a prior outlier probability of 0.05 . 


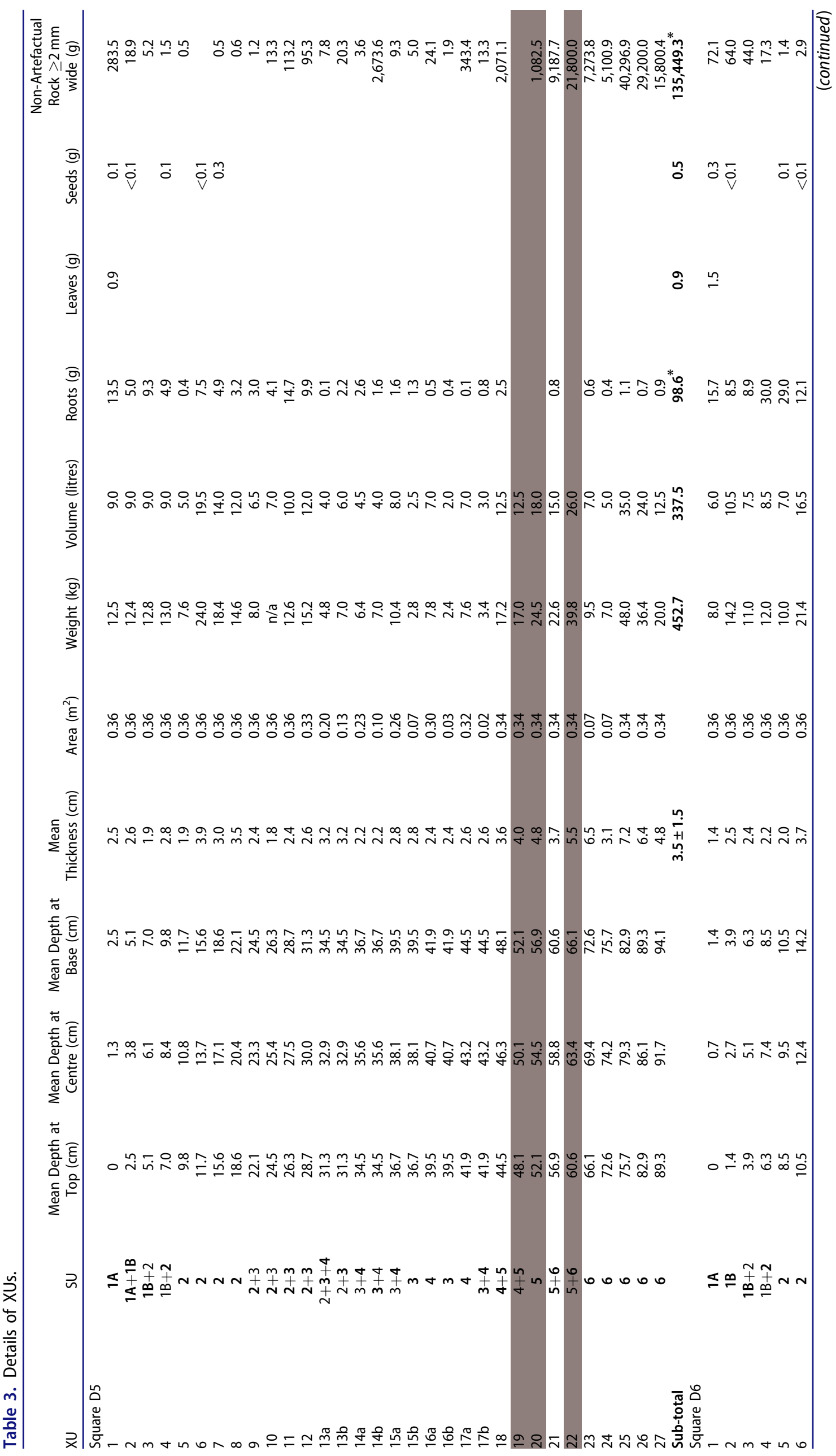




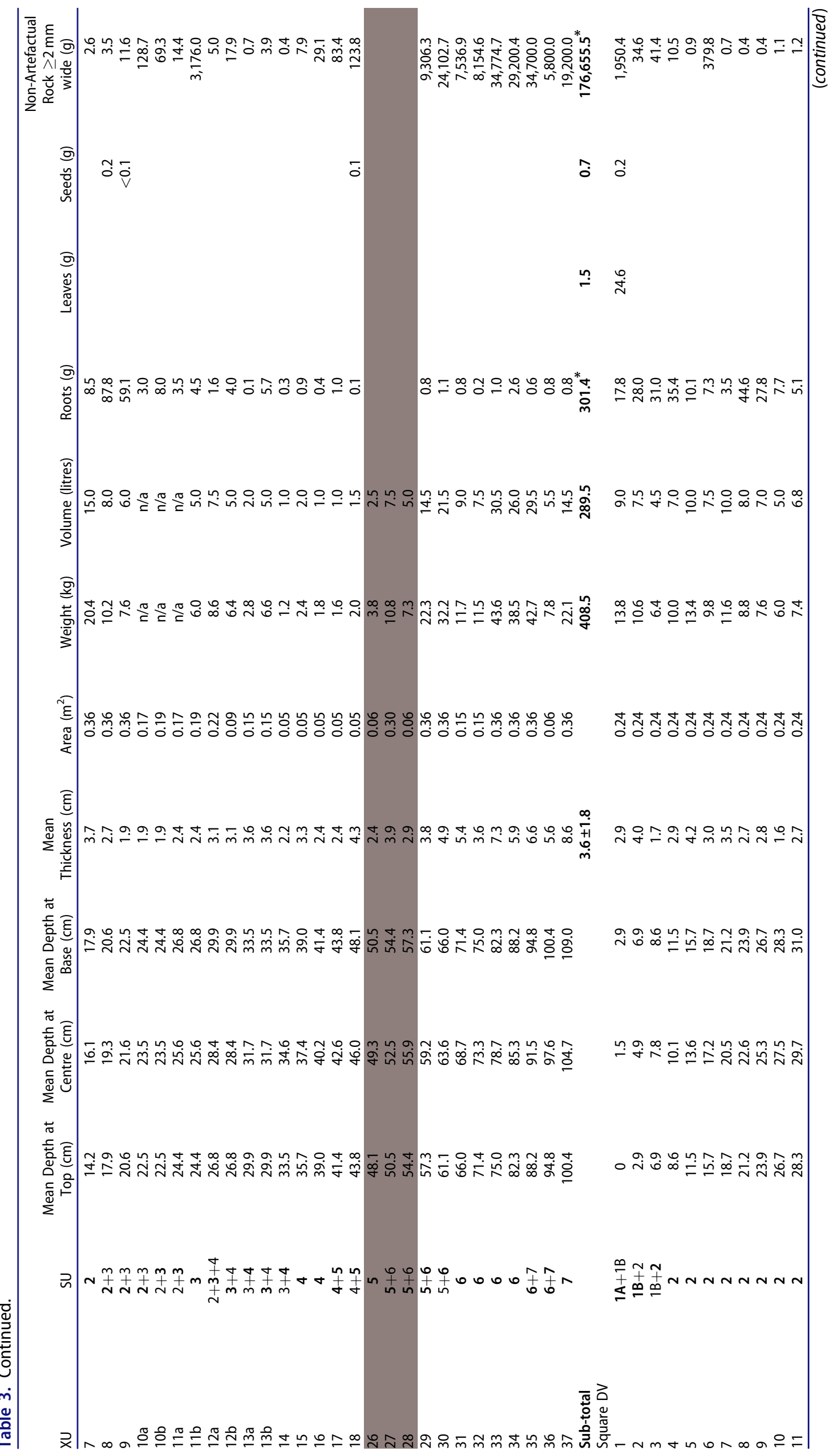




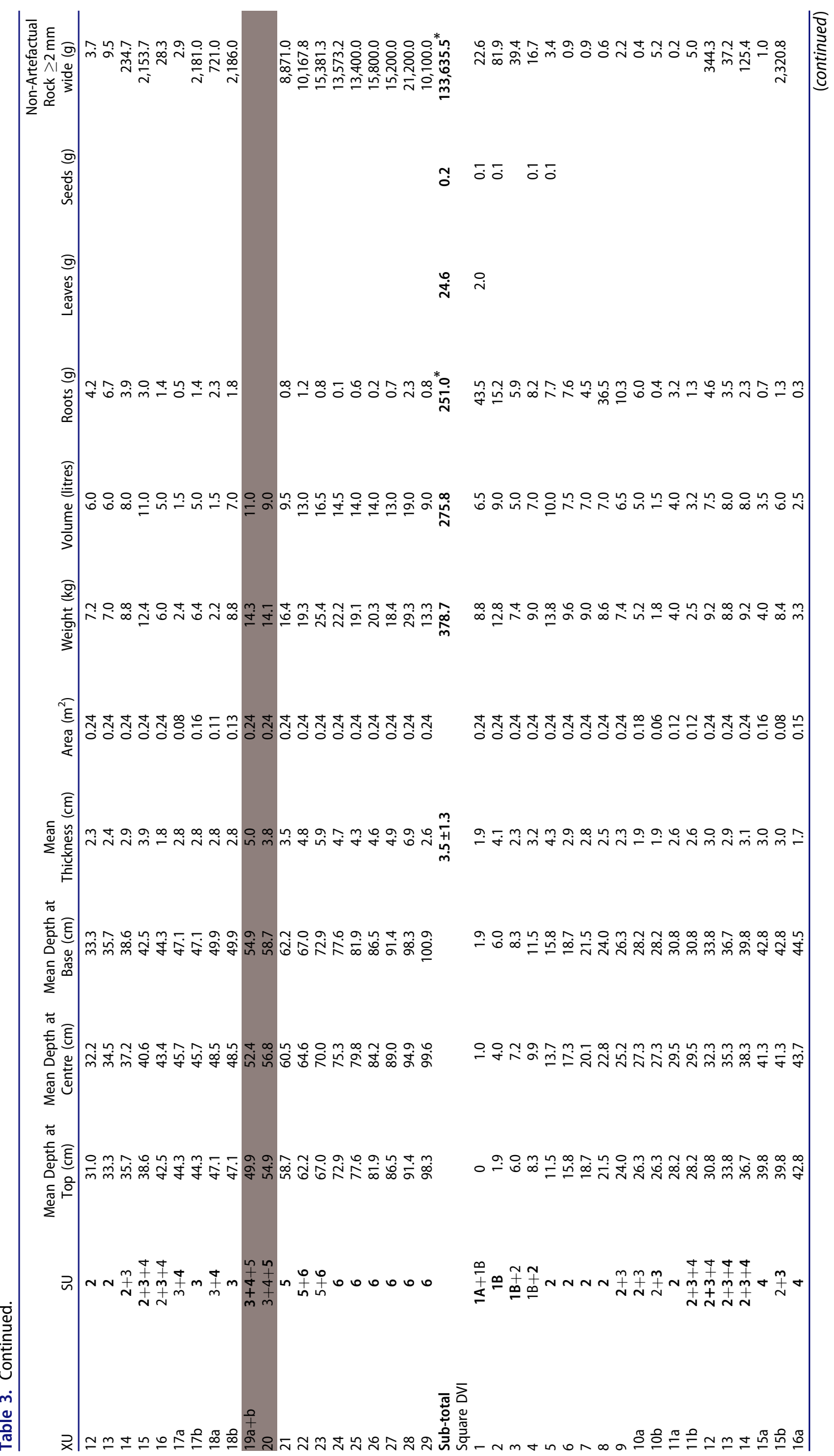




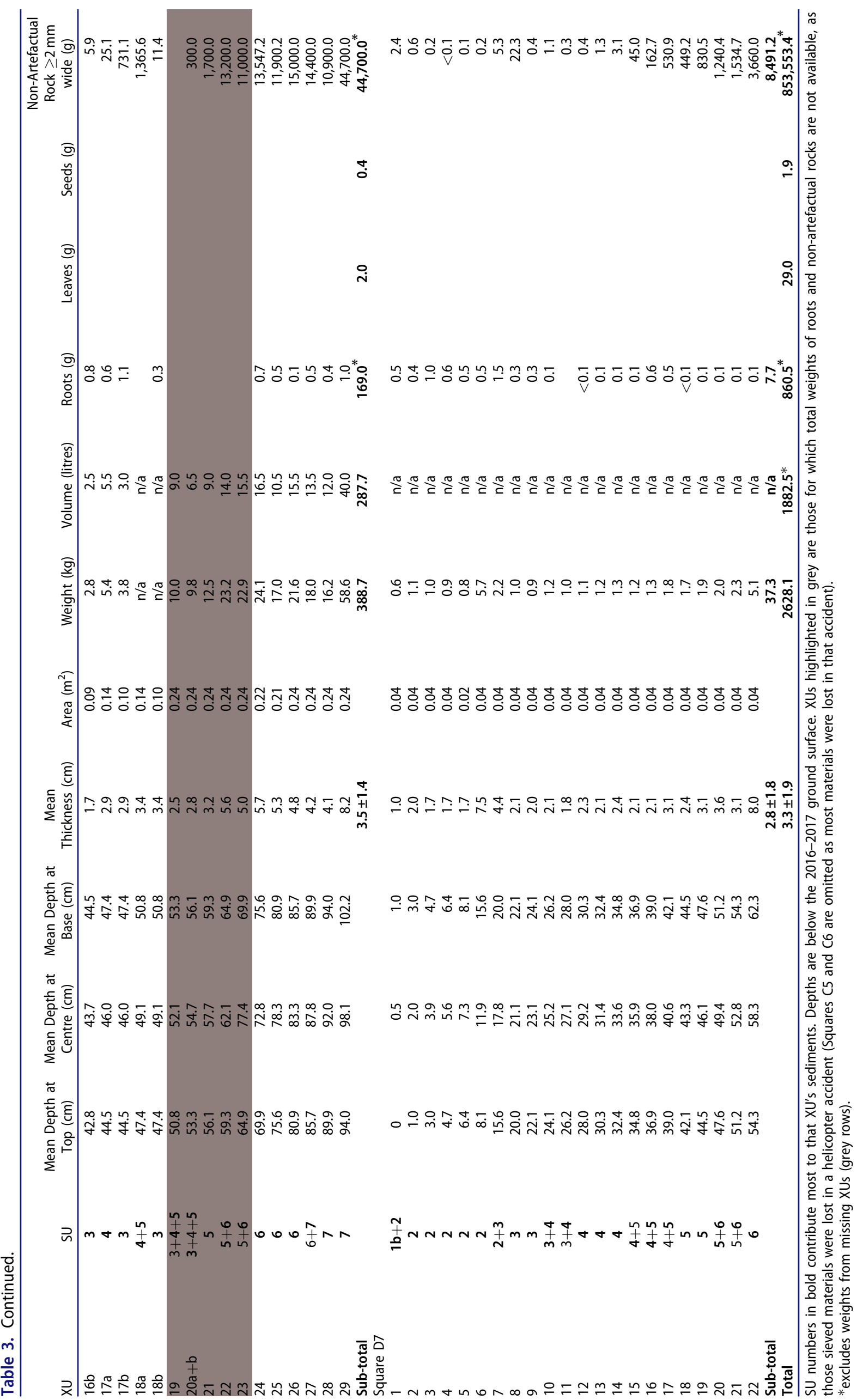


Table 4. Description of sediments by SU, Borologa 1 Squares C5-C6-D5-D6-D7-DV-DVI.

\begin{tabular}{|c|c|c|c|c|}
\hline SU & Typical thickness & Description & $\mathrm{pH}$ & Dry Munsell \\
\hline 1 & SU1A + SU1B: $5-10 \mathrm{~cm}$ & $\begin{array}{l}\text { This layer is divided into two sub-SUs. SU1A is the current } \\
\text { loose surface sand. It is largely devoid of vegetation } \\
\text { growth but contains minor leaf litter. The interface with } \\
\text { SU1B is fairly marked, taking place over c. } 2-3 \mathrm{~cm} \text { depth. } \\
\text { The base of SU1A is uneven as it meets the slightly con- } \\
\text { solidated surface of SU1B. SU1B sediments consist of } \\
\text { loamy sands that are similar to the SU1A sands, albeit } \\
\text { rootlets c. } 1 \mathrm{~mm} \text { in diameter grow in SU1B only. } \\
\text { Sediments in both SU1A and SU1B are homogeneous in } \\
\text { texture and colour. The interface with SU2 is flat but } \\
\text { poorly defined, taking place over } 3-4 \mathrm{~cm} \text { depth. }\end{array}$ & SU1A: 4.8 SU1B: 4.7 & 10YR 5/4 (yellowish brown) \\
\hline 2 & $15-35 \mathrm{~cm}$ & $\begin{array}{l}\text { Slightly compact and poorly consolidated homogeneous } \\
\text { loamy sand. Dry at time of excavation, becoming slightly } \\
\text { more humid with depth. Occasional rootlets up to } 3 \mathrm{~cm} \\
\text { diameter grow at all angles; at c. } 25 \mathrm{~cm} \text { depth, rootlets } \\
\text { tend to grow horizontally at the SU2-SU3 interface. The } \\
\text { base of SU2 is usually well-defined, taking place over a } \\
\text { vertical distance of } 2-4 \mathrm{~cm} \text { with the appearance of SU3. } \\
\text { However, the SU2-SU3 interface is diffuse where the char- } \\
\text { coal-rich SU3 is poorly defined. }\end{array}$ & 4.5 & 7.5YR 5/4 (brown) \\
\hline 3 & $3-15 \mathrm{~cm}$ & $\begin{array}{l}\text { A charcoal-rich hearth layer. The upper surface of SU3 (as it } \\
\text { interfaces with SU2 above it) is not flat; its base interfaces } \\
\text { with SU4 typically over a depth of } 3-4 \mathrm{~cm} \text { and undulates } \\
\text { even more than its upper surface, signalling connecting } \\
\text { charcoal-rich lenses of varying depths. The well-defined } \\
\text { charcoal lenses signal the presence of three adjacent } \\
\text { hearths (one across much of Squares C6 and D6; a second } \\
\text { along the southeastern side of Squares DV and DVI; a } \\
\text { third along the southwestern side of Squares DV and D5 } \\
\text { onto the southeastern edge of Square C5). Each hearth } \\
\text { was spatially continuous with its nearest neighbour, so } \\
\text { that together they constituted a band of ash and charcoal } \\
\text { typically } 3-5 \text { cm-thick. A lack of horizontal and vertical } \\
\text { separation between the hearths - the total absence of } \\
\text { ash-and-charcoal-free sand between them - indicates } \\
\text { their contemporaneity as a single occupational event con- } \\
\text { taining multiple, usually small hearths. }\end{array}$ & 4.5 & $\begin{array}{l}\text { 10YR } 4 / 2 \text { (dark grey- } \\
\text { ish brown) }\end{array}$ \\
\hline 4 & $5-20 \mathrm{~cm}$ & $\begin{array}{l}\text { Slightly more compact loamy sand than in SU1-SU3. } \\
\text { Sediments are homogeneous throughout. The base of } \\
\text { SU4 is flat; the interface with SU5 is marked, taking place } \\
\text { over a vertical distance of } 1-2 \mathrm{~cm} \text {. Rootlets c. } 1 \mathrm{~mm} \text { wide } \\
\text { are present. }\end{array}$ & 4.6 & 7.5YR 5/4 (brown) \\
\hline 5 & $5-15 \mathrm{~cm}$ & $\begin{array}{l}\text { The upper surface of SU5 is reasonably well defined, consist- } \\
\text { ing of compact and moderately consolidated ashy, dark } \\
\text { yellowish brown loamy sand. The SU5 upper and lower } \\
\text { stratigraphic boundaries are generally horizontal from } \\
\text { southwest to northeast, but slant down slightly towards } \\
\text { the southeast. Texture and colour are homogeneous } \\
\text { across the pit and with depth, but the lower part of SU5 } \\
\text { appears more 'chaotic' in the sense that its base is less } \\
\text { regular as it interfaces with the uneven upper levels of } \\
\text { SU6. The 7-10 cm-thick interface with SU6 is diffuse, pen- } \\
\text { etrating into the upper rocks of SU6. At the junction of } \\
\text { Squares C5, C6, D5 and D6, the flat upper surface of the } \\
\text { rock at the base of SU5 is fire-stained (Figure 14), and } \\
\text { charcoal is relatively abundant, indicating the location of } \\
\text { a hearth. }\end{array}$ & 5.1 & $\begin{array}{l}\text { 10YR 4/4 (dark yellow- } \\
\text { ish brown) }\end{array}$ \\
\hline 6 & c. $35 \mathrm{~cm}$ & $\begin{array}{l}\text { A culturally sterile layer of massive rock fall angling down } \\
\text { toward the southeast, but lying horizontally from south- } \\
\text { west to northeast. The sandstone rock is friable, having } \\
\text { fractured in situ and during excavation breaking up in } \\
\text { typically } 5-10 \mathrm{~cm} \text {-thick plates; it was excavated through } \\
\text { in all squares, without reaching bedrock. Rootlets up to c. } \\
1 \mathrm{~cm} \text { in diameter grow in the interstices between frag- } \\
\text { menting rock plates. SU6 represents superimposed large } \\
\text { slabs of rock-fall. The southeast edges of Squares D5 and } \\
\text { D6, onto DV and DVI, mark the area beyond the dripline } \\
\text { and are thus exposed to rainfall. In these squares, much } \\
\text { of the rock is highly fragmented and weathered. }\end{array}$ & 5.2 & 5YR 5/4 (reddish brown) \\
\hline 7 & & $\begin{array}{l}\text { Culturally sterile layer. Large rock slab surface sloping down } \\
\text { southward at the base of the pit. The angle of the slope } \\
\text { suggests that this represents a large collapsed slab of } \\
\text { rock from an originally deeper overhang. The excavation } \\
\text { could not penetrate into this hard rock except in the } \\
\text { upper levels of SU7 in Squares DV and DVI (the more } \\
\text { weathered area beyond the dripline exposed to rain). }\end{array}$ & 5.2 & 5YR 4/4 (dark reddish brown) \\
\hline
\end{tabular}




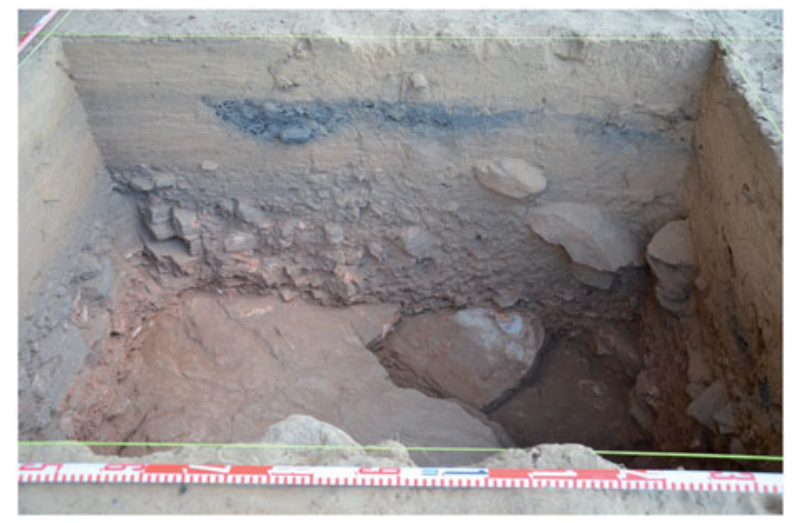

Figure 12. Northeastern wall of Squares C6, D6 and DVI after end of excavation, prior to excavating Square D7 (photo: Bruno David).

This allows outliers to be either too young or too old, and down-weighs their influence in the model.

This model identified two major outliers, Wk45962 and Wk-45969 with outlier probabilities of $100 \%$ and $89 \%$ respectively. The small charcoal sample of Wk-45962 gave a radiocarbon age of $1,938 \pm 16 \mathrm{BP}$, which has been calibrated to $1,930-1,820$ cal BP, a period not otherwise represented in the excavated squares. It probably came from hearth or bushfire charcoal originating nearby, either within the site or from the broader landscape. Wk-45969 came from adjacent to and slightly above the base of a large grindstone in Square D6 (see below); it dates to $2,259 \pm 16 \mathrm{BP}$, calibrated to $2,350-2,180 \mathrm{cal} \mathrm{BP}$. This period is well represented in the excavated squares (the 'Base of SU5' phase), but all the other charcoal samples of that age came from $5-16 \mathrm{~cm}$ deeper than Wk-45969. This latter charcoal sample is interpreted to have been scuffed up by a few centimetres during the positioning of the large grindstone (details below). Although for $89 \%$ of the time these two outlier ages are not included in the model results (because they are down-weighted), at least $11 \%$ of the time they still have influence on the modelled ages and are probably responsible for the low convergence values $(<95 \%)$ generated by the Bayesian algorithms in SU5, indicating many different incompatible solutions to this section of the model (cf. Bronk Ramsey 1995).

The model was re-run without the outliers. This second chronostratigraphic model returned statistically acceptable results with convergence values of $>98 \%$ and no outliers (Table 6). The interval between Phases was also calculated using the 'Interval' command in OxCal (Bronk Ramsey 2018). The results are given in Table 6 and suggest that early in the sequence in this part of the site, campfires were made and/or landscape fires occurred (i.e. producing wood charcoal) every c.
300 years, with more regular visitation to this part of the site fronting the Wanjina paintings after $c$. 640 cal BP.

The results show an age sequence reflecting good chronostratigraphic integrity. The individual calibrated ages and Bayesian analysis each indicate that SU6 and SU7, the deepest two layers consisting of massive roof-fall devoid of cultural materials and charcoal, formed sometime before $3,000-2,500 \mathrm{cal}$ BP. In an adjacent area outside the dripline, Square F5 (see Figure 3) revealed charcoal at c. $125 \mathrm{~cm}$ below surface. It returned a calibrated age range of 3,230-3,070 cal BP (Wk-44397), consistent with and predating SU7. The start of SU5 above the massive SU6 roof-fall layer immediately shows the first dated evidence of human presence in the excavation pit reported in this paper; a hearth was built on the rock surface at the junction of Squares C5, C6, D5 and D6 sometime between 3,000-2,270 cal BP. This was followed by a period of up to 440 years duration (Interval A) when wood charcoal was not produced, and for which there is no evidence of human occupation in this part of the site. Evidence of human presence in the form of stone artefacts associated with charcoal is again evident near the base of SU5 dated within the period 2,370 and 2,110 cal BP; it was then that a large grindstone was positioned in place and first used (see below). There is then a second period without carbon ages, Interval B that lasts 110 to 660 years, after which the bulk of SU5 was laid down sometime between 2,080-1,160 cal BP. Cultural materials in this main SU5 Phase consist of large numbers of flaked stone artefacts. This is followed by Interval C, a period of 120 to 590 -years duration when there are again no signs of burning. Cultural evidence then reappears at the base of SU4, dated within 1,110-760 cal BP, after which there is a fourth hiatus in radiocarbon determinations, Interval D of 170 to 390-years' duration. The SU3 hearth layer is then dated to 630-500 cal BP, immediately followed by the start of SU2 at $480-340 \mathrm{cal}$ BP. SU2 then ends at $450-120$ cal BP with the start of sediment build up in SU1B. SU1B ends between $270 \mathrm{cal} B P$ and the present.

Each of these radiocarbon (read 'burning') Phases is associated with cultural materials, and indeed in some cases at least - most demonstrably the hearth at the base of SU5, and the SU3 hearth layer - the deposition of the charcoal itself can be shown to be from cultural events.

\section{Cultural materials}

Cultural materials were found in all SUs except SU6 and SU7. They fall into six major types: 

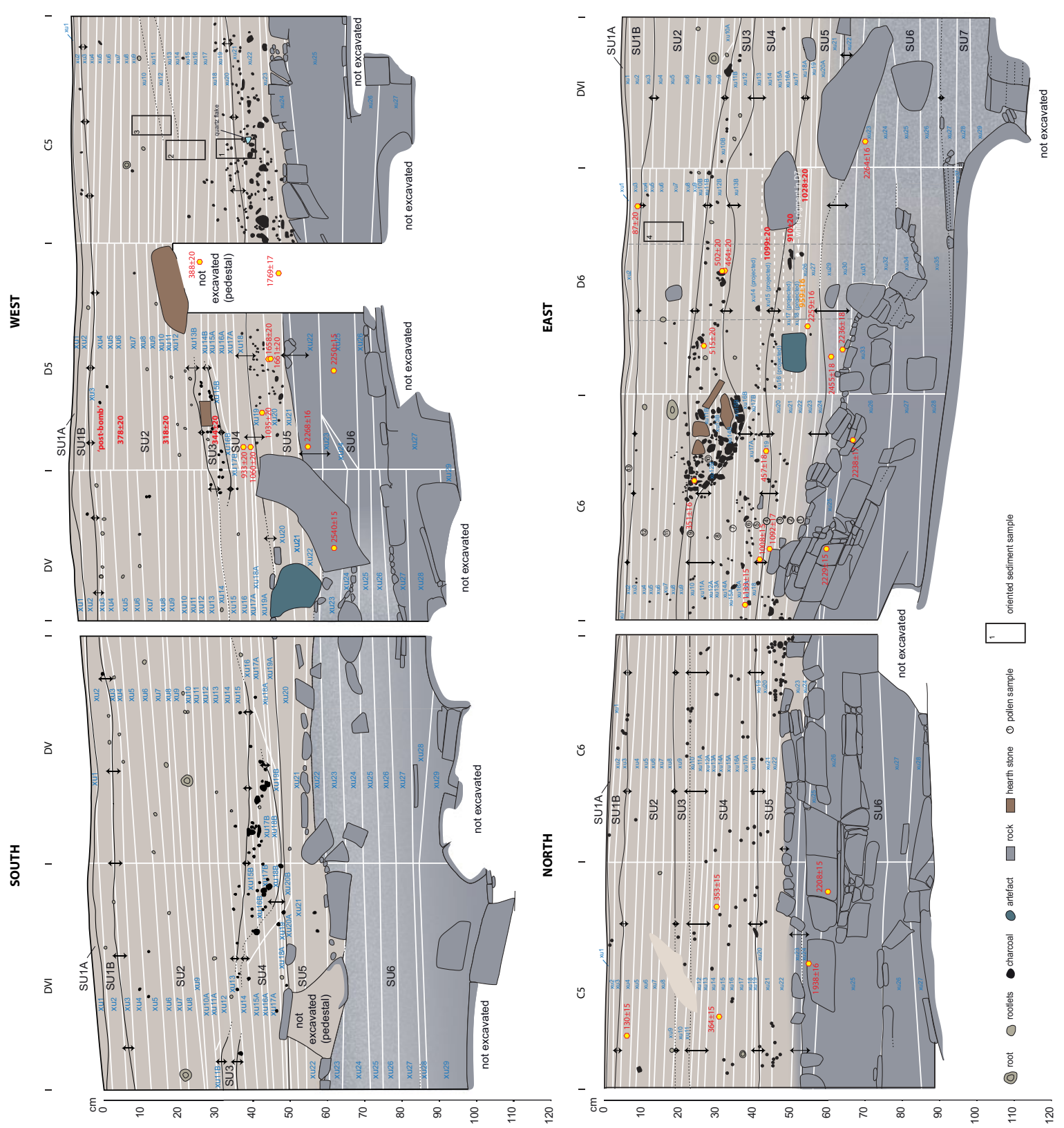

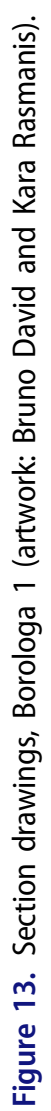




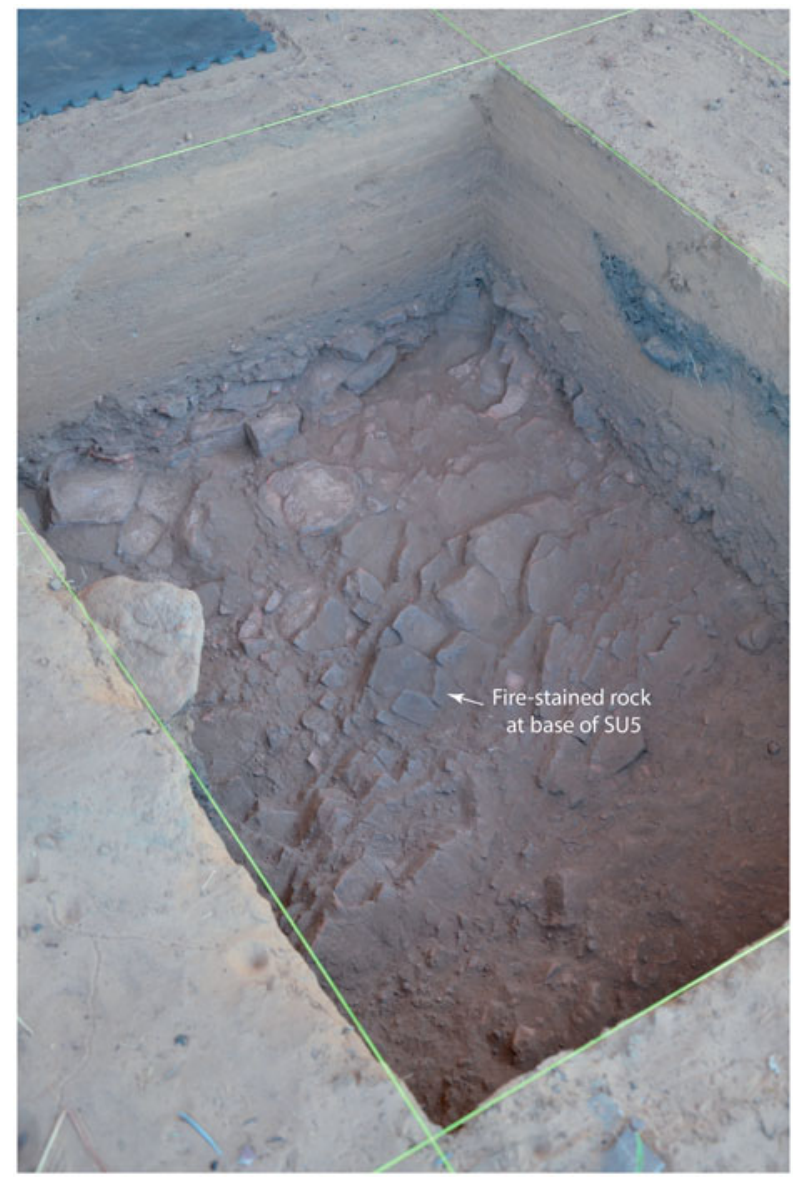

Figure 14. Fire-stained rock surface representing the floor of a hearth at the junction of Squares C5, C6, D5 and D6, base of SU5 (photo: Bruno David).

hearths, flaked stone artefacts, plant-processing basal and top grindstones, a large grindstone installation, earth pigments imported into the site, and small fallen spalls of the rock wall that contain traces of pigment and dried paint drops (Table 7, Figure 16). Stone artefacts are found throughout the cultural sequence except during the four radiocarbon Intervals (A-D) during which there is no evidence of charcoal deposition. In this paper, we focus on the earth pigments and grindstones in chronostratigraphic context.

Three adjacent hearths constitute SU3. The thickest of these, c. $15 \mathrm{~cm}$ thick in Squares C6-D6, was built immediately on top of the then exposed upper surface of a very large grindstone in Square D6, so that the latter's surface became extensively burnt (Figure 17). Each of these three concentrated charcoal lenses contained burnt hearth stones oriented in all directions within the hearth sediments, and a single burnt flat rock up to $25 \mathrm{~cm}$ long placed horizontally at the very top of the hearth, representing a distinctive act of hearth treatment. In Square C5 on the edge of the hearths, the base of a basal grindstone lay flush with the upper surface of the SU3 hearth layer, and an associated topstone lay very slightly lower next to it (Figure 18). There is no stratigraphic separation between the top of the hearth layer and the base of the grindstones (charcoal particles from the hearth layer adhere to the base of the basal grindstone, and the topstone is slightly embedded in SU3). Residue analysis of the basal grindstone's worked surface reveals a dense concentration of starch grains indicating the processing of plants (results to be published separately).

Another, large grindstone has its base located well within the base of SU5 in Square D6. Cultural materials including flaked stone artefacts occur throughout SU5. Determining at exactly which level in SU5, and thus when, this large $219 \mathrm{~kg}$ block that measures $58 \mathrm{~cm}$ long, $50 \mathrm{~cm}$ wide by $27 \mathrm{~cm}$ thick was put in place is not immediately evident, for it would have sunken slightly into the ground when it was first laid down. As it was positioned in place, we can expect what was then the floor to have been scuffed to some degree. A number of critical stratigraphic clues enable us to pinpoint exactly when the grindstone was put in place.

The base of the grindstone became archaeologically exposed in Square D6 XU28, at a depth of $57.7 \mathrm{~cm}$ below datum. The base is flat, as is its parallel, crushed and ground (from the act of pounding and grinding) upper surface. The grindstone also has a faint reddish tinge across its upper surface, presumably from the processing of red ochre. While the base of the grindstone sits in SU5, its upper surface lies $27 \mathrm{~cm}$ higher at the bottom of SU3 being eventually fully buried with charcoal and ash from that major hearth (Figure 17).

The grindstone has been deliberately levelled by the use of three small rocks, each c. $15 \mathrm{~cm}$ long and $10 \mathrm{~cm}$ high, piled one on top of the other to chock its overhanging northwest corner (Figure 17). The base of the lowermost chock rock indicates the level at which the large grindstone was positioned into place. That level of the base of the lowest chock rock lies in XU27, $58.4 \mathrm{~cm}$ below datum, a mere $7 \mathrm{~mm}$ lower than the base of the large grindstone and therefore almost at an identical level, indicating that the grindstone itself did not penetrate much into underlying sediments when it was put in place (keeping in mind that the original ground surface would probably not have been perfectly horizontal). Also in XU27, from $52.7 \mathrm{~cm}$ below datum - i.e. $5.7 \mathrm{~cm}$ above the base of the lowest chock rock - a charcoal sample (Wk45969) was AMS radiocarbon dated (Table 5). It gave an age of $2,259 \pm 16 \mathrm{BP}$, which has been calibrated to $2,350-2,180 \mathrm{cal} \mathrm{BP}$ at $95.4 \%$ probability. Below this, in XU29, two charcoal samples were 


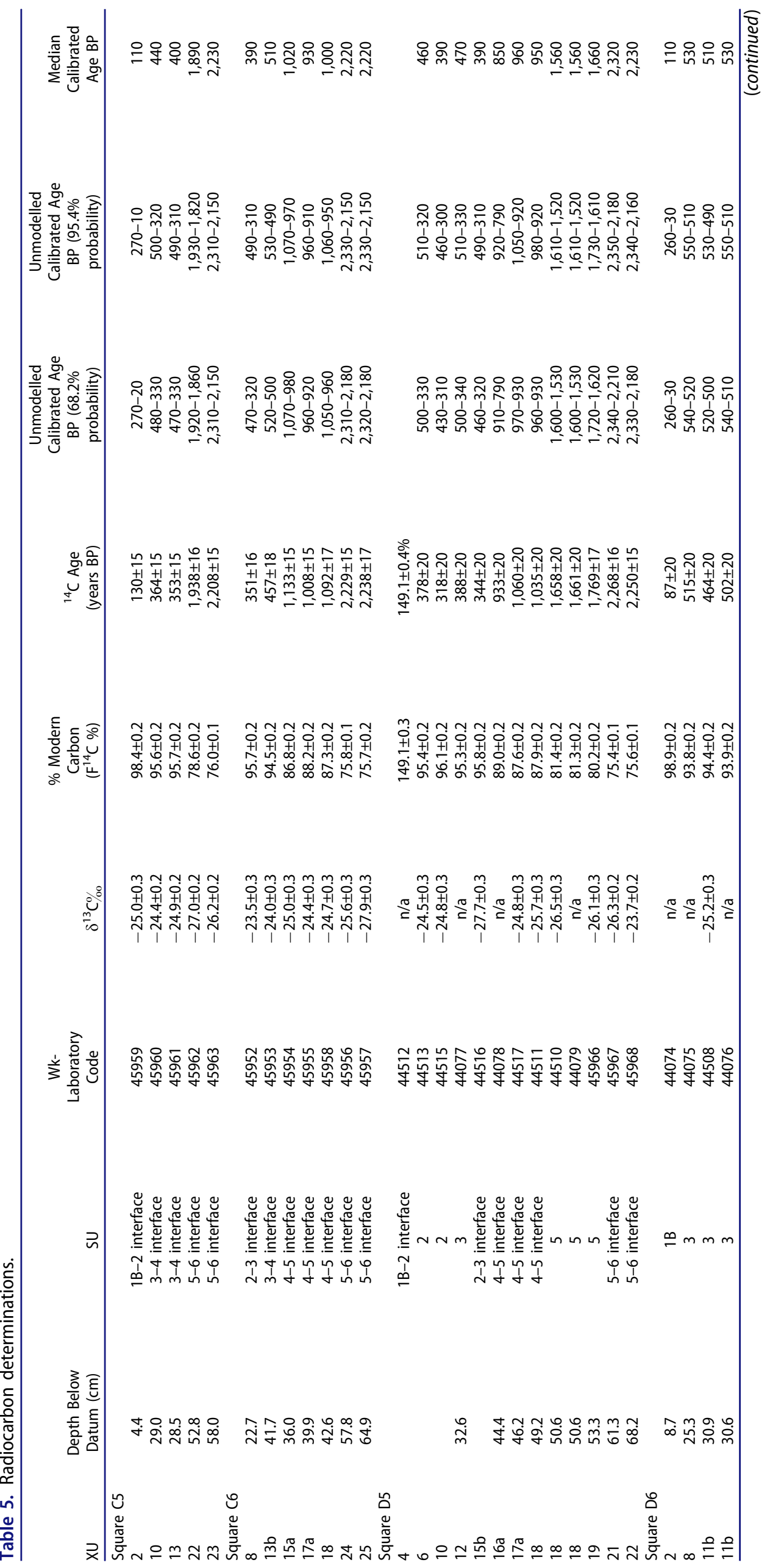




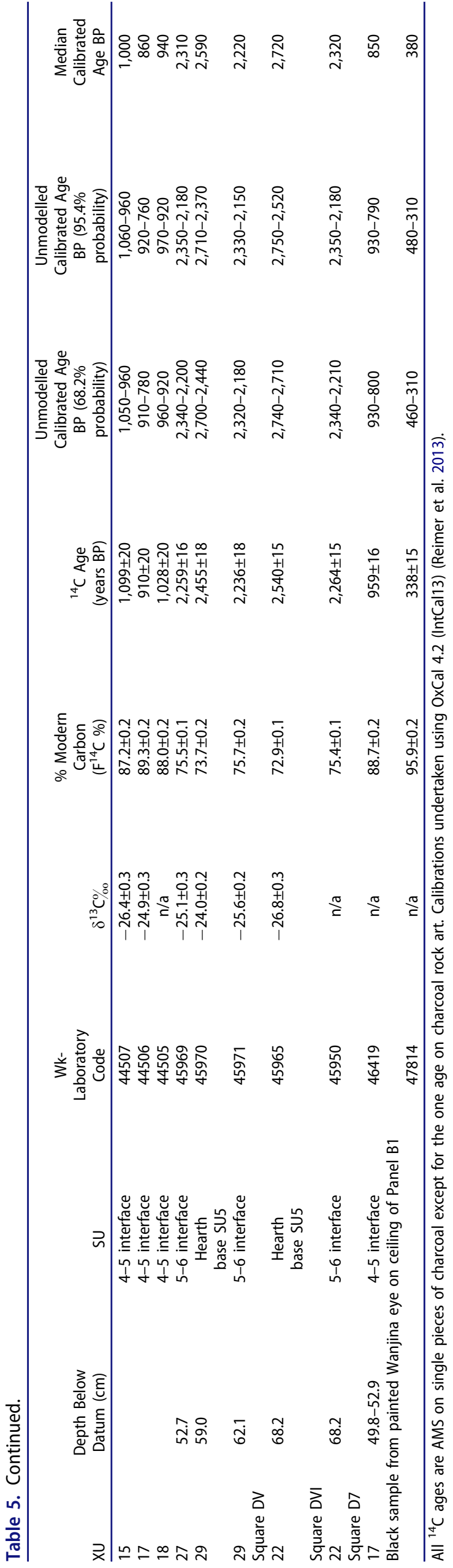

individually dated. Wk-45970 came from $59.0 \mathrm{~cm}$ below the datum (i.e. $6 \mathrm{~mm}$ below the lowest chock rock) and gave an age of 2,455 $\pm 18 \mathrm{BP}$ (calibrated to $2,710-2,370 \mathrm{cal} \mathrm{BP})$. Wk-45971 came from $62.1 \mathrm{~cm}$ below datum (i.e. $3.7 \mathrm{~cm}$ below the lowest chock rock), giving an age of 2,236 $\pm 18 \mathrm{BP}$ (calibrated to $2,330-2,150 \mathrm{cal}$ BP). While Wk-45969 and Wk-45971 represent levels $5.7 \mathrm{~cm}$ above and $3.7 \mathrm{~cm}$ below the base of the lowest chock rock respectively, both give ages within the calibrated probability range $2,350-2,150 \mathrm{cal}$ BP. Wk- 45970 in-between is slightly older. Given the consistent age bracketing of the two younger ages, we interpret these results to mean that the small rocks were positioned to chock the grindstone into place sometime between 2,350-2,150 cal BP, the slightly older, out-of-sequence Wk-45970 age having being scuffed up from slightly deeper sediments during instalment of the grindstone and its chock blocks. This is consistent with the age estimate of 2,370-2,110 cal BP from the Bayesian analysis. Given that the base of the large grindstone itself also lies at this same general stratigraphic level, we conclude that it was put into position, oriented flat ready for use, at that time.

\section{Analysis of buried pigments}

This leaves for discussion (1) the buried small fragments of earth pigment that were processed on-site and that abound through the deposit, (2) the spalls with pigment and (3) the dried paint drops. The spalls and paint drops almost certainly fell into the deposit from the overlying Art Panel B1 rock ceiling. No ochre crayons - pieces of ochre with evidence of striations or bevelled edges - were found in the excavated material.

Excluding the ochre-stained large grindstone itself, in total 56 items with pigment were recovered in situ during the excavation (Figure 19) or during sorting of the sieved excavated sediments.

\section{The small fragments of pigment}

Fifty-two small ( $8-29 \mathrm{~mm}$ long) to tiny (c. $2 \mathrm{~mm}$ long) angular fragments of red ochre (Figures 19 and 20), two pieces of white, and two pieces of red ochre with traces of white adhering to them were excavated. One of the pieces of white pigment was extracted in situ from Square D7 XU17 (Figure 21). It consists of a powdery conglomerated mass with a grainy, porous texture, associated with other white fragments that were more uniform in texture, compact and hard. The largest piece of red ochre weighs $2.5 \mathrm{~g}$. 
OxCal v4.3.2 Bronk Ramsey (2017); r:5 IntCal13 atmospheric curve (Reimer et al 2013)

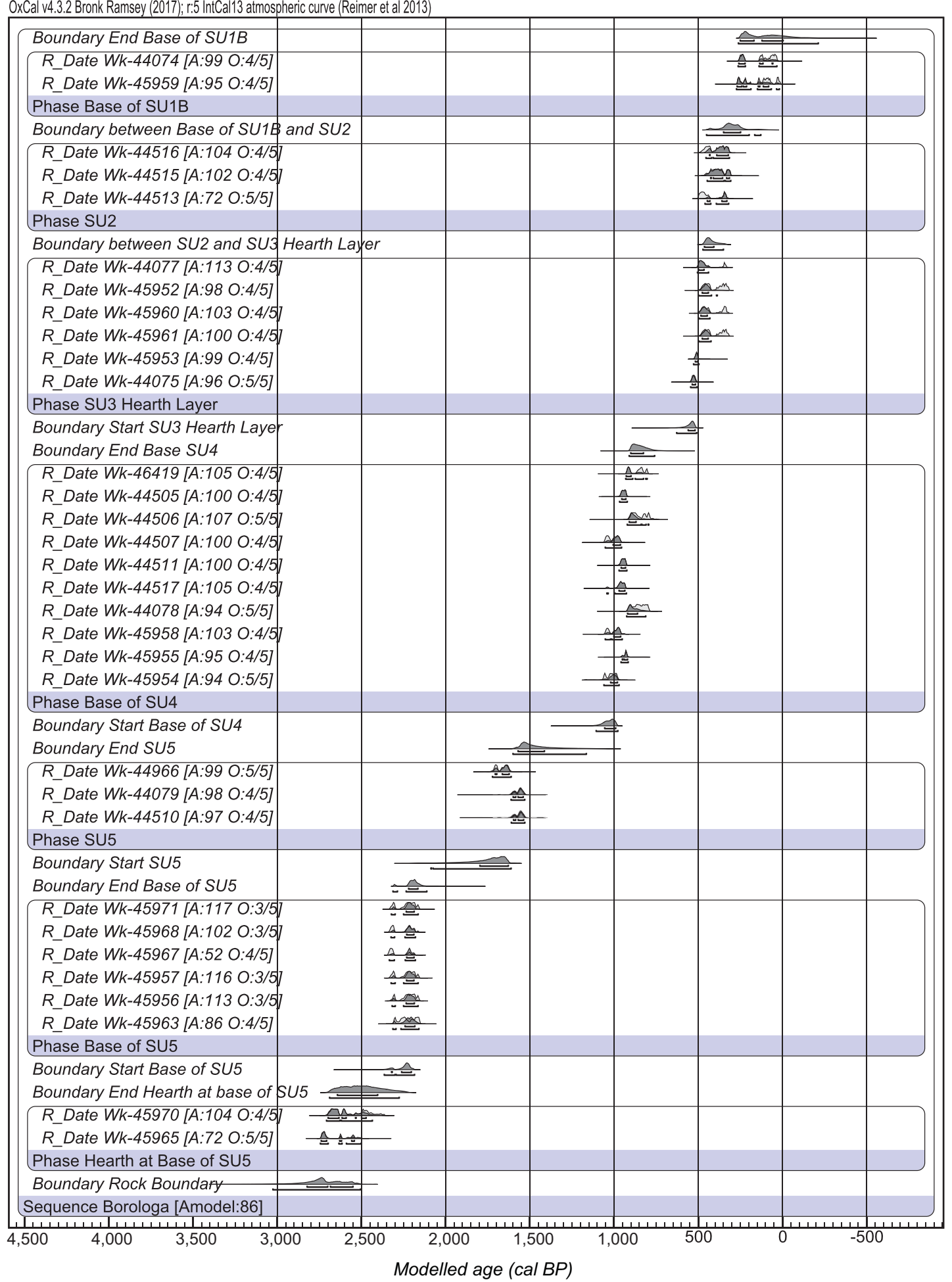

Figure 15. Bayesian age model for cultural levels at Borologa 1. The lighter shaded distributions of the individual calibrations are the unmodelled calibrated ages. Darker outlines represent the results after Bayesian modelling (see text for discussion) (image: Fiona Petchey and Bruno David).

The 56 small fragments of pigment were concentrated in four chronostratigraphic Pigment Horizons, from top to bottom (Figure 16):

- An upper, Pigment Horizon IV, at the base of SU1B, from $2-12 \mathrm{~cm}$ below ground, consisting exclusively of tiny fragments of red ochre $(\mathrm{N}=10$, total weight $=0.53 \mathrm{~g})$. The Bayesian
Sequence Analysis dates this horizon after 450 cal BP.

- Pigment Horizon III that corresponds with the 'SU3 hearth layer' phase of the Bayesian Sequence Analysis (including SU3-SU4 interface) from $17.9-36.7 \mathrm{~cm}$ depth. It dates within $630-340 \mathrm{cal}$ BP. It also consists exclusively of tiny fragments of red ochre $(\mathrm{N}=21$, total weight $=3.98 \mathrm{~g})$. 
Table 6. Modelled results showing chronostratigraphic Phase boundary ages for the top of SU6 to SU1B.

\begin{tabular}{|c|c|c|c|c|}
\hline \multirow{2}{*}{$\begin{array}{l}\text { Boundary divisions } \\
\text { between Phases }\end{array}$} & \multirow{2}{*}{$\begin{array}{c}\text { Calibrated modelled age, } \\
68.2 \% \text { probability }\end{array}$} & \multirow{2}{*}{$\begin{array}{c}\text { Calibrated modelled age, } \\
95.4 \% \text { probability }\end{array}$} & \multicolumn{2}{|c|}{ Interval between Phases (SU) } \\
\hline & & & $68.2 \%$ probability & $95.4 \%$ probability \\
\hline 'End Base of SU1B' & $260-0 \mathrm{cal} \mathrm{BP}$ & $270-190 \mathrm{cal} \mathrm{BP}$ & & \\
\hline $\begin{array}{l}\text { 'Between Base of SU1B } \\
\text { and SU2' }\end{array}$ & $350-240 \mathrm{cal} \mathrm{BP}$ & $450-120 \mathrm{cal} \mathrm{BP}$ & & \\
\hline $\begin{array}{l}\text { 'Between SU2 and SU3 } \\
\text { Hearth Layer' }\end{array}$ & $470-400$ cal BP & $480-340$ cal BP & & \\
\hline 'Start SU3 Hearth Layer' & $560-510 \mathrm{cal} \mathrm{BP}$ & $630-500 \mathrm{cal} \mathrm{BP}$ & & \\
\hline Duration of Interval D & & & $260-370$ years & $170-390$ years \\
\hline 'End Base of SU4’ & $910-820$ cal BP & $910-760$ cal BP & & \\
\hline 'Start Base of SU4' & $1,060-990 \mathrm{cal} \mathrm{BP}$ & $1,110-970 \mathrm{cal} \mathrm{BP}$ & & \\
\hline Duration of Interval C & & & $370-560$ years & $120-590$ years \\
\hline 'End SU5' & $1,570-1,400$ cal BP & $1,600-1,160$ cal BP & & \\
\hline 'Start SU5' & $1,800-1,620 \mathrm{cal} \mathrm{BP}$ & $2,080-1,610$ cal BP & & \\
\hline Duration of Interval B & & & $370-580$ years & $110-660$ years \\
\hline 'End Base of SU5' & $2,220-2,160$ cal BP & $2,320-2,110$ cal BP & & \\
\hline 'Start Base of SU5' & $2,320-2,200$ cal BP & $2,370-2,180 \mathrm{cal} \mathrm{BP}$ & & \\
\hline Duration of Interval A & & & $120-390$ years & $10-440$ years \\
\hline 'End Hearth at base of SU5' & $2,640-2,400$ cal BP & $2,690-2,270$ cal BP & & \\
\hline Rock boundary & $2,820-2,540$ cal BP & $3,000-2,500 \mathrm{cal} \mathrm{BP}$ & & \\
\hline
\end{tabular}

Ages in bold indicate maximum start and end dates for each phase.

- Pigment Horizon II (36.7-48.1 cm depth), in SU4, consisting of both red ochre fragments $(\mathrm{N}=14$, total weight $=1.70 \mathrm{~g})$, a small piece of red pigment with stains of white pigment on its surface $(0.15 \mathrm{~g})$, and the small mass of white clay pigment $(0.50 \mathrm{~g})$ deposited in Square D7 near the edge of the large grindstone. It corresponds with the 'Base of SU4' phase (including the SU4-SU5 interface) of the Bayesian Sequence Analysis, dated within 1,110-760 cal BP.

- Pigment Horizon I $(47.3-67.0 \mathrm{~cm}$ depth) has seven red ochre fragments (total weight $=3.50 \mathrm{~g}$ ), one piece of red pigment with adhering trace of white $(0.06 \mathrm{~g})$, and one white fragment $(0.13 \mathrm{~g})$. It corresponds with the 'SU5' phase of the Bayesian Sequence Analysis, dated within $2,080-1,160$ cal BP.

These pigment fragments are interpreted as byproducts of the processing of larger ochre pieces for paint-making. As larger blocks were crushed and ground, tiny pieces became scattered along the edges of the grindstone, falling onto the surrounding ground. Both red and white appear to have been processed on the grindstone, as evident by the two pieces of red with adhering traces of white. The small mass of white pigment is an exception: it was placed $15 \mathrm{~cm}$ from the northeastern edge of the grindstone, when the grindstone's flat working surface was still $23 \mathrm{~cm}$ above what was then the floor (Figure 21).

Most of the red, and white, earth pigment fragments were located surrounding the large grindstone of Square D6, just outside the overhang that has the Wanjina paintings with white background. The two excavation squares furthest from the grindstone and from the overhanging ceiling with white background - Squares DV and DVI - did not have any pieces of white pigment. All the pigment fragments from Pigment Horizons I-III date to times when the large grindstone's upper surface was exposed above ground and available for use. Those levels contain 46 of the 56 fragments (82\%). However, the pigment from the uppermost Pigment Horizon IV could not have been processed from that grindstone, as its highest point had already been completely buried by $16 \mathrm{~cm}$ of ash and loamy sand by that stage. We suggest the 10 tiny red ochre fragments from Pigment Horizon IV were produced either through crushing and grinding on a portable grindstone (since removed) or from one or more of the three grinding patches on the flat bedrock a short distance inside the shelter under the overhang.

\section{The paint drops}

Two samples consisting of small masses (weighing $0.04 \mathrm{~g}$ and $0.19 \mathrm{~g}$, respectively) of densely packed disintegrating sandstone grains, with the outer grains adhered together by white pigment, were recovered from Square C6 XU17A. They came from a part of the excavation pit located vertically under the white-painted ceiling. We interpret these as small pieces of disintegrating sandstone that fell from the ceiling during painting, and call them 'paint drops' because it is the dry white pigment that weakly holds the outer grains together (for an example of dried paint drops excavated elsewhere in northern Australia, see David et al. 2017). The paint drops date to Pigment Horizon II (within 1,110-760 cal $\mathrm{BP})$, the same level containing the small mass of 
Table 7. Square A. Distribution of excavated cultural materials.

\begin{tabular}{|c|c|c|c|c|c|c|c|c|c|c|c|c|}
\hline \multirow[b]{2}{*}{$X U$} & \multirow[b]{2}{*}{ SU } & \multirow{2}{*}{$\frac{\text { Charcoal }}{\mathrm{g}}$} & \multicolumn{2}{|c|}{ Burnt Rock } & Ston & $\begin{array}{l}\text { d } \\
\text { efacts }\end{array}$ & & & & & $\operatorname{Rec}$ & \\
\hline & & & $\#$ & $\mathrm{~g}$ & $\#$ & $\mathrm{~g}$ & $\#$ & g & $\#$ & $\mathrm{~g}$ & $\#$ & $\mathrm{~g}$ \\
\hline Square D5 & & & & & & & & & & & & \\
\hline 1 & $1 \mathrm{~A}$ & 5.2 & & & 9 & 0.4 & & & & & & \\
\hline 2 & $1 A+1 B$ & 2.7 & & & 4 & 0.4 & & & & & 1 & 0.05 \\
\hline 3 & $1 \mathrm{~B}+2$ & 0.3 & & & 2 & 0.2 & & & & & & \\
\hline 4 & $1 B+2$ & 0.2 & & & & & & & & & & \\
\hline 5 & 2 & $<0.1$ & & & & & & & & & & \\
\hline 6 & 2 & 0.2 & & & & & & & & & & \\
\hline 7 & 2 & 0.1 & & & 1 & $<0.1$ & & & & & & \\
\hline 8 & 2 & 0.3 & & & & & & & & & & \\
\hline 9 & $2+3$ & 0.2 & & & 1 & $<0.1$ & & & & & & \\
\hline 10 & $2+3$ & 0.3 & & & & & & & & & & \\
\hline 11 & $2+3$ & 4.0 & & & & & & & & & & \\
\hline 12 & $2+3$ & 17.1 & & & 5 & 1.4 & & & & & & \\
\hline $13 a$ & $2+3+4$ & 0.9 & & & 1 & $<0.1$ & & & & & & \\
\hline $13 b$ & $2+3$ & 41.0 & & & 2 & $<0.1$ & & & & & & \\
\hline $14 a$ & $3+4$ & 1.2 & & & & & & & & & & \\
\hline $14 b$ & $3+4$ & 73.4 & & & & & & & & & & \\
\hline $15 a$ & $3+4$ & 1.8 & & & 3 & 0.1 & & & & & 1 & 0.01 \\
\hline $15 b$ & 3 & 84.8 & & & 2 & $<0.1$ & & & & & & \\
\hline $16 a$ & 4 & 1.5 & & & 11 & 0.6 & & & & & & \\
\hline $16 b$ & 3 & 8.3 & & & & & & & & & 1 & 0.03 \\
\hline $17 a$ & 4 & 3.2 & & & 41 & 3.7 & & & & & 1 & 0.03 \\
\hline $17 b$ & $3+4$ & 1.3 & & & 7 & 0.3 & & & & & & \\
\hline 18 & $4+5$ & 41.8 & & & 178 & 45.4 & & & & & 5 & 0.27 \\
\hline 19 & $4+5$ & 0.1 & & & & & & & & & & \\
\hline 20 & 5 & 1.3 & & & & & & & & & & \\
\hline 21 & $5+6$ & 11.7 & & & 201 & 35.7 & & & & & & \\
\hline 22 & $5+6$ & & & & & & & & & & & \\
\hline 23 & 6 & $<0.1$ & & & & & & & & & & \\
\hline 24 & 6 & & & & & & & & & & & \\
\hline 25 & 6 & & & & & & & & & & & \\
\hline 26 & 6 & & & & & & & & & & & \\
\hline 27 & 6 & & & & & & & & & & & \\
\hline Sub-total & & 303.1 & & & 468 & 88.7 & & & & & 9 & 0.39 \\
\hline Square D6 & & & & & & & & & & & & \\
\hline 1 & $1 \mathrm{~A}$ & 5.6 & & & 17 & 1.3 & & & & & & \\
\hline 2 & $1 \mathrm{~B}$ & 6.8 & & & 19 & 1.7 & & & & & 4 & 0.09 \\
\hline 3 & $1 \mathrm{~B}+2$ & 0.1 & & & 9 & 1.9 & & & & & 1 & 0.02 \\
\hline 4 & $1 \mathrm{~B}+2$ & 0.5 & & & 1 & $<0.1$ & & & & & & \\
\hline 5 & 2 & 0.2 & & & 6 & 0.7 & & & & & & \\
\hline 6 & 2 & 0.6 & & & & & & & & & & \\
\hline 7 & 2 & 10.4 & & & & & & & & & & \\
\hline 8 & $2+3$ & 1.9 & & & & & & & & & 1 & 0.02 \\
\hline 9 & $2+3$ & 3.3 & & & 1 & $<0.1$ & & & & & & \\
\hline 10a & $2+3$ & 4.3 & & & 3 & 0.3 & & & & & & \\
\hline $10 b$ & $2+3$ & 73.0 & & & & & & & & & 3 & 2.22 \\
\hline $11 a$ & $2+3$ & 1.2 & & & 1 & 0.1 & & & & & & \\
\hline $11 \mathrm{~b}$ & 3 & 112.3 & & & 2 & 0.1 & & & & & 2 & 0.36 \\
\hline $12 a$ & $2+3+4$ & 2.1 & & & 1 & 0.4 & & & & & & \\
\hline $12 b$ & $3+4$ & 0.3 & & & & & & & & & & \\
\hline $13 a$ & $3+4$ & 0.4 & & & 1 & $<0.1$ & & & & & & \\
\hline $13 b$ & $3+4$ & 11.5 & & & 1 & 0.1 & & & & & 1 & 0.02 \\
\hline 14 & $3+4$ & 0.2 & & & & & & & & & & \\
\hline 15 & 4 & 1.4 & & & & & & & & & & \\
\hline 16 & 4 & 3.9 & & & 5 & 0.5 & & & & & & \\
\hline 17 & $4+5$ & 12.0 & & & 6 & 0.7 & & & & & 2 & 0.47 \\
\hline 18 & $4+5$ & 5.3 & & & 29 & 2.6 & & & & & 1 & 0.10 \\
\hline 26 & 5 & & & & & & & & & & & \\
\hline 27 & $5+6$ & 0.2 & & & & & & & & & & \\
\hline 28 & $5+6$ & $<0.1$ & & & & & & & & & & \\
\hline 29 & $5+6$ & 27.4 & & & 132 & 15.4 & & & & & $1^{*}$ & 0.06 \\
\hline 30 & $5+6$ & 4.1 & & & 35 & 1.7 & & & & & & \\
\hline 31 & 6 & $<0.1$ & & & 10 & 0.3 & & & & & & \\
\hline 32 & 6 & $<0.1$ & & & 2 & 0.1 & & & & & & \\
\hline 33 & 6 & & & & & & & & & & & \\
\hline 34 & 6 & & & & 1 & 0.2 & & & & & & \\
\hline 35 & $6+7$ & & & & & & & & & & & \\
\hline 36 & $6+7$ & & & & & & & & & & & \\
\hline 37 & 7 & & & & & & & & & & & \\
\hline Sub-total & & 289.3 & & & 282 & 28.4 & & & & & 15 & 3.30 \\
\hline Square DV & & & & & & & & & & & & \\
\hline 1 & $1 A+1 B$ & 5.2 & & & 5 & 0.8 & & & & & & \\
\hline 2 & $1 \mathrm{~B}+2$ & 2.0 & & & 7 & 4.8 & & & & & & \\
\hline 3 & $1 \mathrm{~B}+2$ & 0.2 & & & 6 & 0.5 & & & & & 1 & 0.24 \\
\hline 4 & 2 & 0.3 & & & & & & & & & & \\
\hline
\end{tabular}


26 B. DAVID ET AL.

Table 7. Continued.

\begin{tabular}{|c|c|c|c|c|c|c|c|c|c|c|c|c|}
\hline \multirow[b]{2}{*}{$X U$} & \multirow[b]{2}{*}{ SU } & \multirow{2}{*}{$\frac{\text { Charcoal }}{\mathrm{g}}$} & \multicolumn{2}{|c|}{ Burnt Rock } & \multicolumn{2}{|c|}{$\begin{array}{c}\text { Flaked } \\
\text { Stone Artefacts }\end{array}$} & & tone & & & $\operatorname{Rec}$ & \\
\hline & & & $\#$ & $\mathrm{~g}$ & $\#$ & $\mathrm{~g}$ & $\#$ & $\mathrm{~g}$ & $\#$ & $\mathrm{~g}$ & $\#$ & $\mathrm{~g}$ \\
\hline 5 & 2 & 0.3 & & & & & & & & & & \\
\hline 6 & 2 & 0.1 & & & 1 & $<0.1$ & & & & & & \\
\hline 7 & 2 & 0.1 & & & & & & & & & & \\
\hline 8 & 2 & & & & & & & & & & & \\
\hline 9 & 2 & & & & & & & & & & & \\
\hline 10 & 2 & & & & & & & & & & & \\
\hline 11 & 2 & 0.1 & & & & & & & & & & \\
\hline 12 & 2 & 0.2 & & & & & & & & & & \\
\hline 13 & 2 & 2.1 & & & & & & & & & & \\
\hline 14 & $2+3$ & 27.2 & & & 1 & 0.1 & & & & & & \\
\hline 15 & $2+3+4$ & 20.0 & & & 4 & 0.2 & & & & & & \\
\hline 16 & $2+3+4$ & 27.1 & & & 2 & $<0.1$ & & & & & & \\
\hline $17 a$ & $3+4$ & 0.3 & & & 2 & 0.2 & & & & & & \\
\hline $17 \mathrm{~b}$ & 3 & 86.1 & & & 1 & $<0.1$ & & & & & & \\
\hline $18 a$ & $3+4$ & 3.2 & & & 49 & 4.2 & & & & & 4 & 0.10 \\
\hline $18 b$ & 3 & 67.9 & & & 13 & 0.9 & & & & & & \\
\hline $19 a+b$ & $3+4+5$ & & & & & & & & & & & \\
\hline 20 & $3+4+5$ & 0.4 & & & & & & & & & & \\
\hline 21 & 5 & 8.2 & & & 180 & 63.1 & & & & & 2 & 0.21 \\
\hline 22 & $5+6$ & 13.7 & & & 131 & 66.4 & & & & & 1 & 0.08 \\
\hline 23 & $5+6$ & 1.0 & & & 57 & 65.5 & & & & & & \\
\hline 24 & 6 & $<0.1$ & & & 5 & 0.2 & & & & & & \\
\hline 25 & 6 & & & & & & & & & & & \\
\hline 26 & 6 & & & & 1 & $<0.1$ & & & & & & \\
\hline 27 & 6 & & & & 1 & 0.1 & & & & & & \\
\hline 28 & 6 & & & & & & & & & & & \\
\hline 29 & 6 & & & & & & & & & & & \\
\hline $\begin{array}{l}\text { Sub-total } \\
\text { Square DVI }\end{array}$ & & 265.8 & & & 466 & 207.3 & & & & & 8 & 0.63 \\
\hline 1 & $1 A+1 B$ & 0.2 & & & 2 & 0.1 & & & & & & \\
\hline 2 & 1B & 5.0 & & & 17 & 1.9 & & & & & 1 & 0.07 \\
\hline 3 & $1 \mathrm{~B}+2$ & 1.0 & & & 7 & 0.4 & & & & & 1 & 0.02 \\
\hline 4 & $1 \mathrm{~B}+2$ & 1.1 & & & 4 & 0.2 & & & & & 1 & 0.04 \\
\hline 5 & 2 & 1.2 & & & & & & & & & & \\
\hline 6 & 2 & & & & & & & & & & & \\
\hline 7 & 2 & 0.2 & & & 1 & $<0.1$ & & & & & & \\
\hline 8 & 2 & 0.1 & & & & & & & & & & \\
\hline 9 & $2+3$ & 3.8 & & & & & & & & & & \\
\hline $10 a$ & $2+3$ & 0.8 & & & & & & & & & & \\
\hline $10 \mathrm{~b}$ & $2+3$ & 4.1 & & & & & & & & & & \\
\hline $11 a$ & 2 & $<0.1$ & & & & & & & & & & \\
\hline $11 \mathrm{~b}$ & $2+3+4$ & 22.3 & & & & & & & & & & \\
\hline 12 & $2+3+4$ & 6.6 & & & & & & & & & & \\
\hline 13 & $2+3+4$ & 16.8 & & & 2 & 0.1 & & & & & 6 & 1.14 \\
\hline 14 & $2+3+4$ & 31.3 & & & & & & & & & & \\
\hline $15 a$ & 4 & 0.7 & & & & & & & & & & \\
\hline $15 b$ & $2+3$ & 74.9 & & & 4 & 0.3 & & & & & & \\
\hline $16 a$ & 4 & 1.7 & & & 1 & $<0.1$ & & & & & & \\
\hline $16 b$ & 3 & 44.2 & & & & & & & & & & \\
\hline $17 a$ & 4 & 1.1 & & & 6 & 0.2 & & & & & & \\
\hline $17 \mathrm{~b}$ & 3 & 71.7 & & & & & & & & & & \\
\hline $18 a$ & $4+5$ & & & & & & & & & & & \\
\hline $18 b$ & 3 & 14.6 & & & 3 & 0.2 & & & & & & \\
\hline 19 & $3+4+5$ & $<0.1$ & & & & & & & & & & \\
\hline $20 a+b$ & $3+4+5$ & 0.4 & & & & & & & & & & \\
\hline 21 & 5 & 0.1 & & & & & & & & & & \\
\hline 22 & $5+6$ & & & & & & & & & & & \\
\hline 23 & $5+6$ & & & & & & & & & & & \\
\hline 24 & 6 & $<0.1$ & & & 15 & 3.4 & & & & & & \\
\hline 25 & 6 & & & & 3 & 0.1 & & & & & & \\
\hline 26 & 6 & & & & 2 & 0.3 & & & & & & \\
\hline 27 & $6+7$ & & & & 1 & $<0.1$ & & & & & & \\
\hline 28 & 7 & & & & & & & & & & & \\
\hline 29 & 7 & & & & & & & & & & & \\
\hline $\begin{array}{l}\text { Sub-total } \\
\text { Square D7 }\end{array}$ & & 304.2 & & & 68 & 7.5 & & & & & 9 & 1.27 \\
\hline 1 & $1 b+2$ & 0.4 & & & 1 & 0.4 & & & & & & \\
\hline 2 & 2 & 0.2 & & & 1 & 0.1 & & & & & & \\
\hline 3 & 2 & 0.1 & & & & & & & & & & \\
\hline 4 & 2 & 0.1 & & & 1 & $<0.1$ & & & & & & \\
\hline 5 & 2 & 0.1 & & & & & & & & & & \\
\hline 6 & 2 & 0.1 & 1 & 4854.8 & 1 & 0.1 & & & & & & \\
\hline 7 & $2+3$ & 6.8 & & & 1 & 0.1 & 1 & 423.2 & & & & \\
\hline 8 & 3 & 8.1 & & & & & & & & & & \\
\hline 9 & 3 & 5.4 & & & & & & & & & & \\
\hline
\end{tabular}


Table 7. Continued.

\begin{tabular}{|c|c|c|c|c|c|c|c|c|c|c|c|c|}
\hline \multirow[b]{2}{*}{$X U$} & \multirow[b]{2}{*}{ SU } & \multirow{2}{*}{$\frac{\text { Charcoal }}{\mathrm{g}}$} & \multicolumn{2}{|c|}{ Burnt Rock } & \multicolumn{2}{|c|}{$\begin{array}{c}\text { Flaked } \\
\text { Stone Artefacts }\end{array}$} & \multicolumn{2}{|c|}{ Grindstone } & \multicolumn{2}{|c|}{$\begin{array}{c}\text { White } \\
\text { Pigment }\end{array}$} & \multicolumn{2}{|c|}{ Red Ochre } \\
\hline & & & $\#$ & $\mathrm{~g}$ & $\#$ & $\mathrm{~g}$ & $\#$ & g & \# & g & $\#$ & $\mathrm{~g}$ \\
\hline 10 & $3+4$ & 1.5 & & & & & & & & & & \\
\hline 11 & $3+4$ & 0.2 & & & & & & & & & & \\
\hline 12 & 4 & 0.1 & & & & & & & & & & \\
\hline 13 & 4 & 0.3 & & & 2 & 0.1 & & & & & 1 & 0.05 \\
\hline 14 & 4 & 0.7 & & & 3 & 0.2 & & & & & & \\
\hline 15 & $4+5$ & 0.8 & & & 6 & 0.2 & & & & & & \\
\hline 16 & $4+5$ & 1.4 & & & 15 & 7.1 & & & & & & \\
\hline 17 & $4+5$ & 5.2 & & & 29 & 3.5 & & & 1 & 0.50 & 3 & 0.36 \\
\hline 18 & 5 & 2.9 & & & 25 & 2.4 & & & & & $1 *$ & 0.15 \\
\hline 19 & 5 & 1.1 & & & 14 & 1.0 & & & & & & \\
\hline 20 & $5+6$ & 0.1 & & & 3 & 0.3 & & & & & & \\
\hline 21 & $5+6$ & $<0.1$ & & & & & & & & & & \\
\hline 22 & 6 & & & & & & & & & & & \\
\hline Sub-total & & 35.7 & 1 & 4854.8 & 102 & 15.6 & 1 & 423.2 & 1 & 0.50 & 5 & 0.56 \\
\hline Total & & 1268.5 & 1 & 4854.8 & 1813 & 397.0 & 1 & 423.2 & 1 & 0.50 & 46 & 6.15 \\
\hline
\end{tabular}

XUs highlighted in grey list the saved in situ cultural materials only: the sieved materials were lost in the helicopter-drop and could not, therefore, be included (Squares C5 and C6 are omitted as most materials were lost in that accident).

*Red pigment with trace of white.

white pigment in Square D7 XU17 on the other side of the large grindstone (described above).

\section{The fallen spalls}

Two small broken pieces of sandstone have white pigment on one side (rather than embedded in the rock), presumed to be spall flakes from the Wanjina art panel with the white background immediately overhead. Like the two paint drops described above, one $(0.17 \mathrm{~g})$ comes from Square C6 XU17A, the other from $4.2 \mathrm{~cm}$ deeper in the sandy deposit of XU19 in the same square. They both come from Pigment Horizon II that also contains the paint drops of Square C6 and the mass of white pigment near the grindstone in Square D7. Like the two paint drops, we interpret these two small spalls of white-painted sandstone as having fallen from the ceiling while it was being painted (see also Hughes 1976). They probably fell during or around the time of the same painting event as the paint drops. They consist of small spalls that were less disintegrated than the paint drops, so that the white paint remained more on the surface of the sand grains.

\section{Pigment analyses}

Geochemical analyses of excavated and potential source pigment samples were undertaken to characterise the excavated samples with a mind to eventually connect the excavated pigments to the on-rock paintings, and to sources (Table 8 ). We note that the paintings on the walls of Borologa 1 have not been systematically sampled for pigment analysis, so in this paper, our results are used to determine the nature and variability of pigments used, and relationships with a nearby source.
Eight of the excavated red pigment, five of the white, and one of the red with a surface trace of white pigments were analysed, including the small mass of white excavated from Square D7 XU17 (Figure 21), and a pigment source from two locations on the opposite bank of the Drysdale River (Figure 22). These samples were characterised using X-Ray Fluorescence spectrometry (pXRF) and Field Emission Scanning Electron Microscopy (SEM) (Table 8, Figure 23). The geochemistry of the excavated white pigments is comparable to that of the nearby source location on the opposite side of the Drysdale River, while that of the red samples is also consistent with a local geomorphic source (see Appendix A for details of the geochemistry).

\section{Direct dating of a Wanjina painting}

An AMS radiocarbon age was also obtained on a small, exfoliating fragment of the left, black eye of a Wanjina painting on Art Panel B1 adjacent to the excavation squares. Such sampling of Wanjina motifs is rarely allowed because of their ongoing significance to local Traditional Owners. In this case, permission was granted due to the collaborative nature of the research and mutual interest in the results. The grey pigment of the eye shows clear striations indicating application by brush. Denser, black fragments across the eye and its outline suggest that the eye was originally painted black, but with time this pigment has mostly fallen off, leaving the underlying layer of white pigment stained grey. The eye was encircled by a red line that partially overlies the grey, but there are no clear instances of its overlying any of the remaining denser black regions. The 'halo' of the Wanjina has been repainted and slightly altered in its 


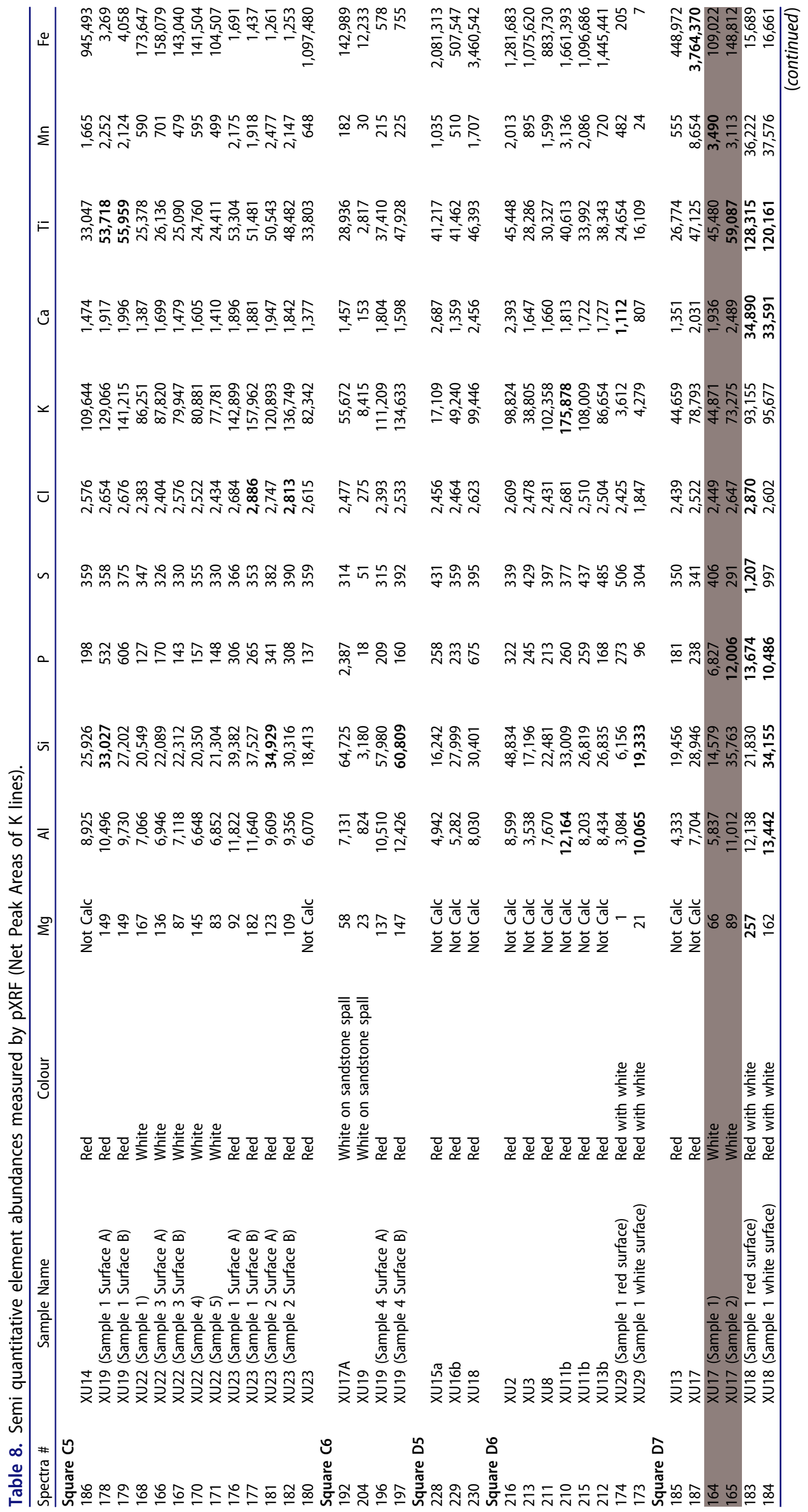




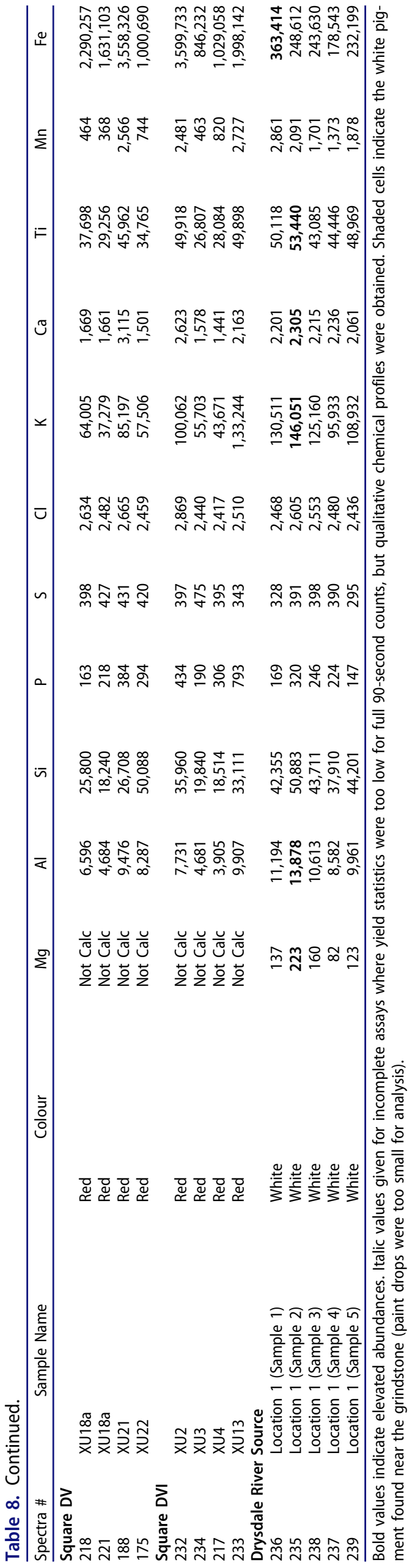

position. The body outline has been similarly altered from an earlier version (Figure 24(B)).

The black eye sample consists of charcoal whose structure could be made out under magnification. It gave a radiocarbon determination of $338 \pm 15 \mathrm{BP}$ (Wk-47814), calibrated to $460-310 \mathrm{cal}$ BP $($ median $=380 \mathrm{cal} \mathrm{BP})$ at $68.2 \%$ probability $($ Table 5$)$. Superimposed over this Wanjina image is a simple sickle-shaped non-figurative element in a very dark red-brown colour, so the radiocarbon determination for the black eye reveals both the age of a late painting event for the eye of the Wanjina, and a maximum age for the superimposing (i.e. later) repainting of its red halo and the re-alignment of the body. It also represents a minimum age for the underlying white pigment.

Phase SU2 of the excavation sequence dates to between 470 and $240 \mathrm{cal} \mathrm{BP}$. The Phase SU3 hearth layer dates to between 560 and $400 \mathrm{cal} \mathrm{BP}$. The age range covered by Wk- 47814 falls between 460 and $310 \mathrm{cal} \mathrm{BP}$, so could conceivably fall within either excavation phase given the limited age control obtained from a single date obtained directly from the rock painting of a Wanjina, but provides the greatest statistical match with Phase SU2. As the dated black charcoal from the eye superimposes (and is, therefore, younger than) the most recent of the two white paint layers on the ceiling, the radiocarbon result for the black of the eye is consistent with the evidence for white painting activity revealed by the buried fragments of white pigment, including the two dried white paint drops and the two small rock spalls with white pigment, almost all of which come from Pigment Horizon II (dated within 1,110-760 cal BP). Some small white pigment samples from the earlier Pigment Horizon I (dated within 2,080-1,160 cal BP) indicate at least two phases of white painting near Art Panel B1, consistent with the two layers of white observed on the ceiling. These results push back in time by a few hundred years what we previously knew of the age of white backgrounds associated with Wanjina paintings, which first appear at Borologa 1 by at least $1,160 \mathrm{cal} B P$ and possibly as early as 2,080 cal BP.

\section{Conclusion}

Despite its considerable interest, rock art often remains poorly integrated into standard archaeological narratives. This is often because the age of the art is poorly understood, and the Kimberley is no exception (but see, for example, Green et al. 2017; Ross et al. 2016). Understanding the chaîne opératoire or operational sequence involved in the production of paint, from procurement to 

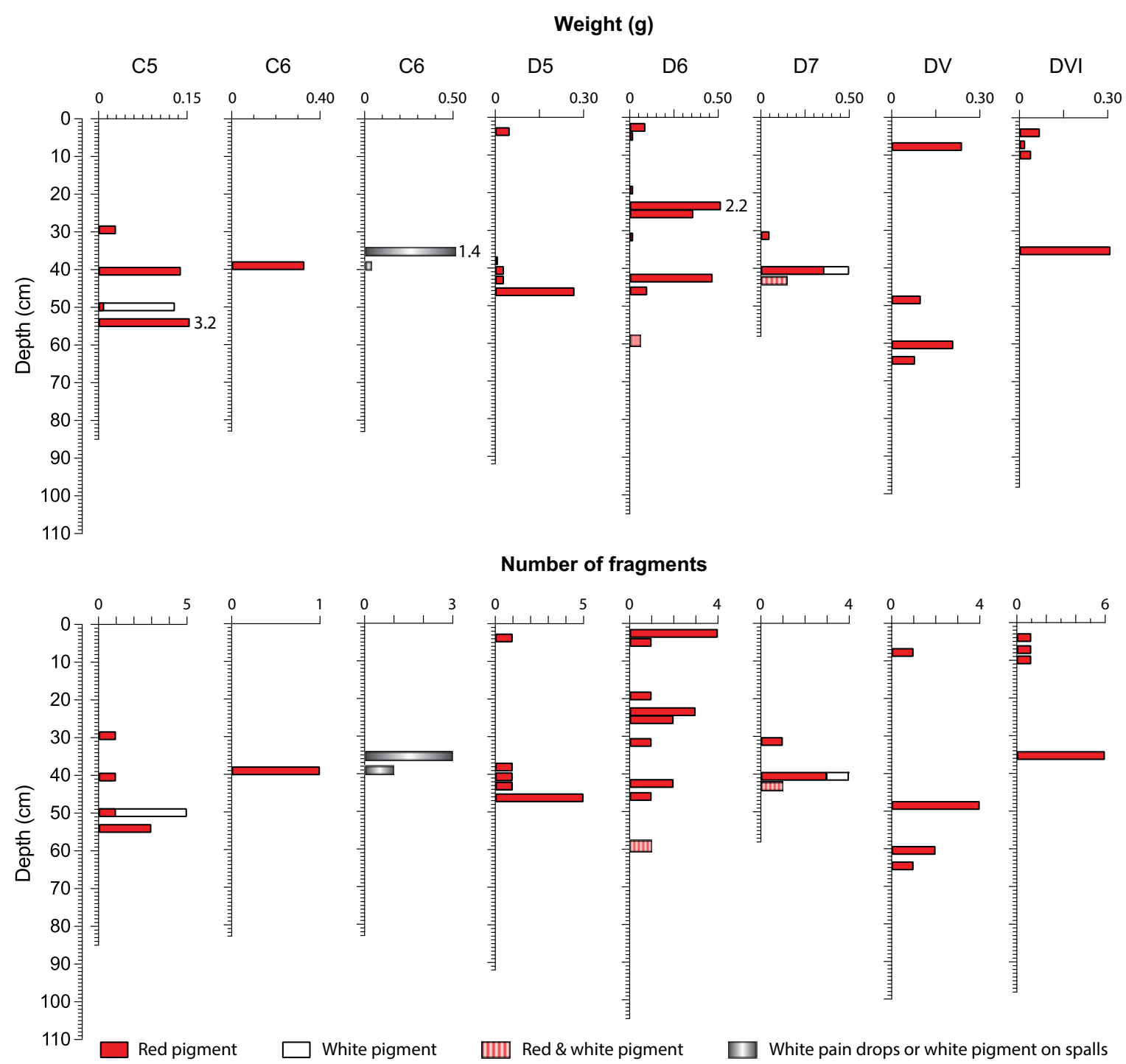

\section{Number of fragments}
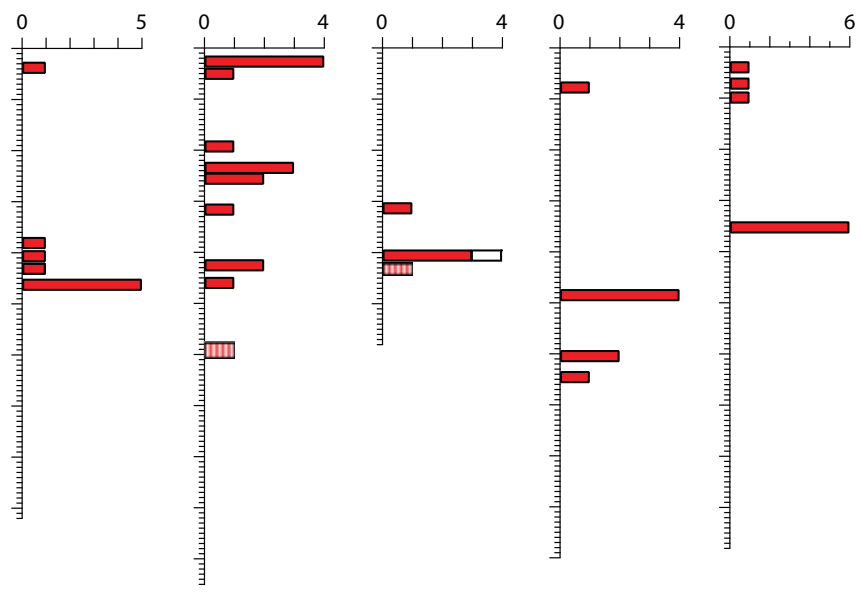

血 Red \& white pigment

White pain drops or white pigment on spalls

Figure 16. Distribution of pigment by excavation square (image: Jerome Mialanes and Bruno David).
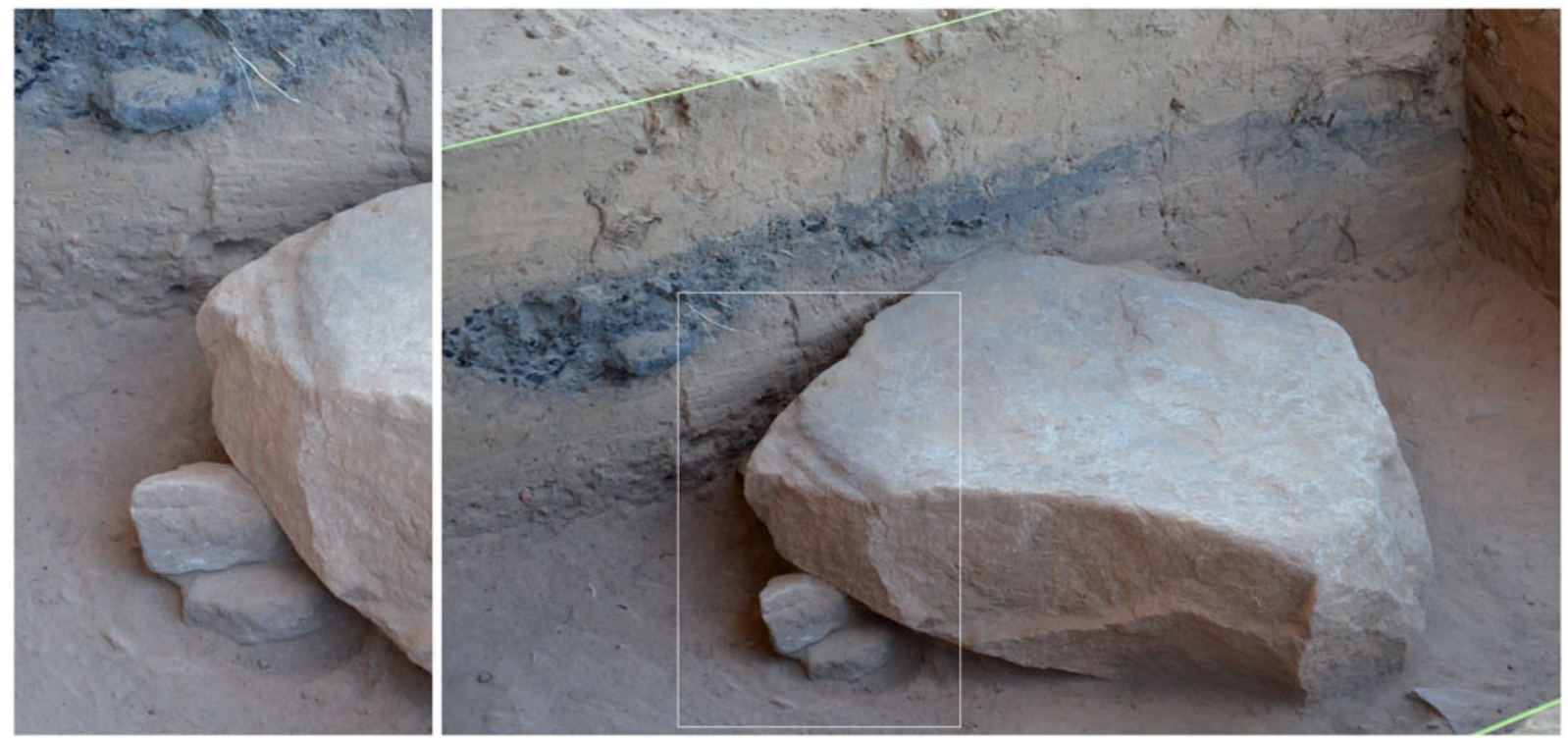

Figure 17. Large grindstone in Square D6, showing its in situ horizontal positioning by the two upper of three chock rocks at its northwestern end (photos: Bruno David). 


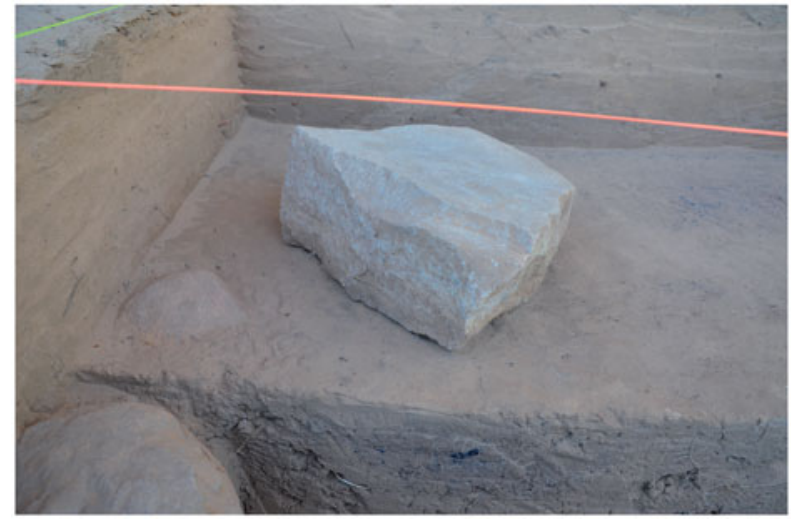

Figure 18. Plant processing basal grindstone before lifting (its base just exposed, flush with the top of the SU3 hearth layer) and topstone (partly buried, middle of lefthand side) from Square $C 5$, excavation in progress (photo: Bruno David).

processing to application, is also of considerable value to archaeology. A common theme is that the successful investigation of each of these - dating, sourcing, production sequence - requires the retrieval of fine-grained information on the pigments at stake. For wall paintings at Borologa 1 Art Panel B1, for example, the presence of superimposed Wanjina with the same but slightly offset orientation as the underlying ones suggests that the aim may not have been only to revitalise the old image by repainting or hiding it, but also to newly highlight and perform its revitalisation. For buried samples, the retrieval of fine-grained information means the employment of finer excavation methods than is often applied, with a careful eye to the strategic positioning of excavation squares, as well as to the retrieval of tiny fragments from pigment processing and potentially of dried paint drops from the application of paint on rock walls or ceilings (see also McNiven et al. 2009). Such dried paint drops, however, will only be seen in situ with finer-grained excavation methods than currently used by most researchers. In short, excavation methods need to be tuned to the recovery of tiny samples produced during processing and paint application, such as the crushing and grinding of ochre, and the residues of painting events (paint drops and roof spalls).

At Borologa 1, the structurally recognisable hearth at the base of SU5 dates between $3,000-2,500 \mathrm{cal}$ BP and 2,690-2,270 cal BP, and the one that makes up SU3 dates within $630-500 \mathrm{cal} \mathrm{BP}$. The large grindstone was installed between 2,370-2,180 cal BP and 2,320-2,110 cal $\mathrm{BP}$, although its upper (grinding) surface remained exposed and usable above the gradually accumulating sediments surrounding it until

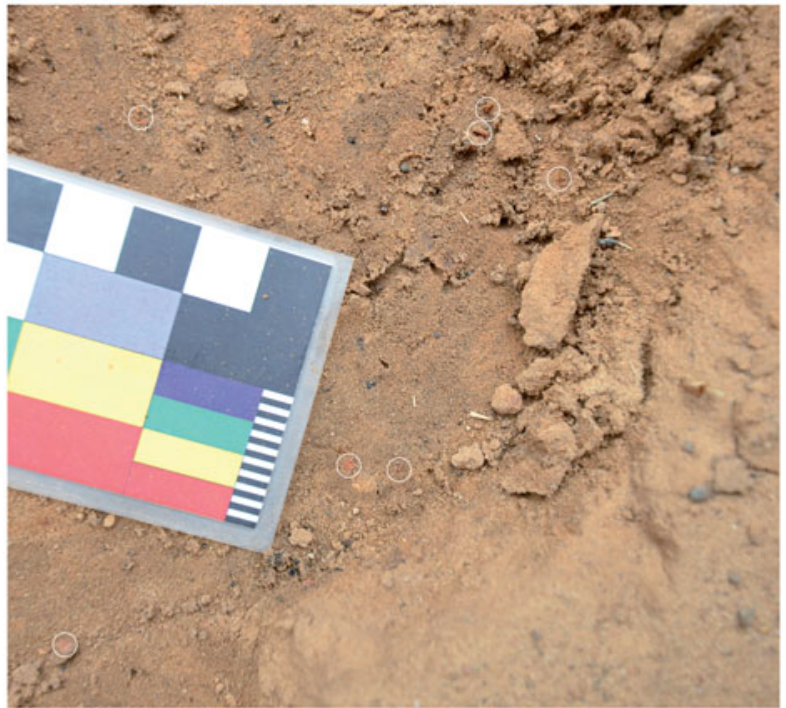

Figure 19. Tiny fragments of red ochre (identified in white circles) exposed by the sweep of the trowel in Square D5 $\mathrm{XU17}$, excavation in progress. The finer scale is in millimetre increments (photo: Bruno David).

630-500 cal BP, when it finally became covered by the SU3 hearth in Square D6. Dozens of tiny pigment fragments were recovered around the large, deliberately installed and levelled grindstone. Here the pigment fragments are by-products of the crushing and grinding of red ochre and (in all likelihood locally extracted) white clay in the making of paint. However, their value is more than the accidental debris of manufacture. Rather, they are by-products that enable us to venture into an archaeology of the painting event itself, providing insights into dating the creation of artworks and understanding their periodic retouching, the evidence of their enduring cosmological significance. Dried paint drops under Art Panel B1's painted ceiling also testify to the event, the chronological pattern strengthened by the contemporaneity of the drops and white fragments as indicated by their exact chronostratigraphic correspondence across excavation squares on either side of a large grindstone.

It is notable that, while the large, installed grindstone that furnished the part of the site adjacent to the painted ceiling was a focal point for the production of pigment during the early phases of paint production, during Pigment Horizon IV, it would already have been buried and could not have been used. Rather, the upper horizon of tiny fragments of red ochre signals either that a portable grindstone was once used and then removed, leaving behind on the ground the by-products of this latest episode of paint production, or that tiny fragments of red ochre became scattered during 
UPPER PIGMENT PHASE: $450-120$ cal BP to Present (= within the past ca. 500 years)

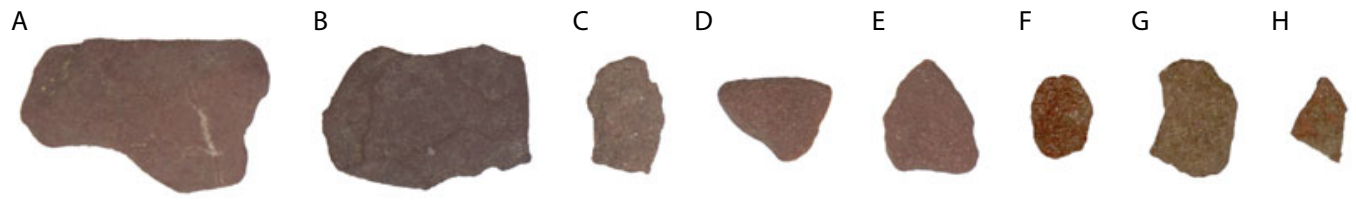

MIDDLE PIGMENT PHASE: $630-500$ to $480-340$ cal BP (= between ca. $700-550$ and 550-400 years ago)

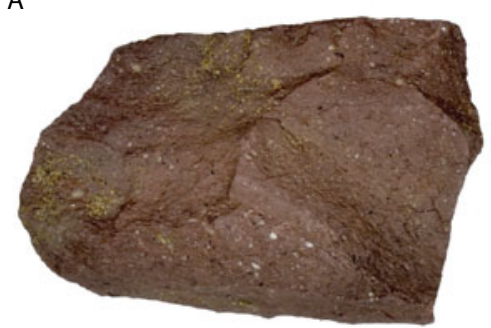

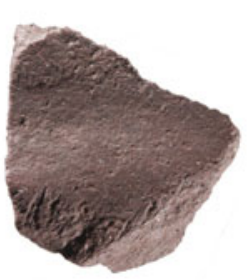

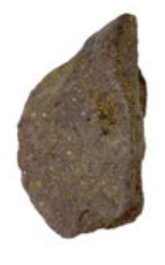

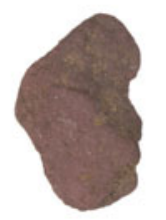

$\mathrm{K}$

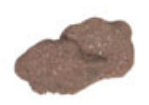

I

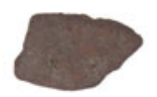

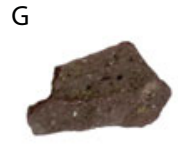

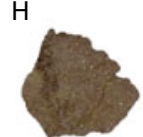

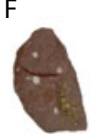

LOW

A

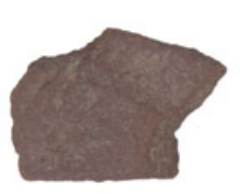

B

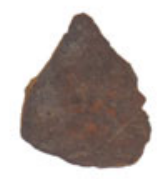

C

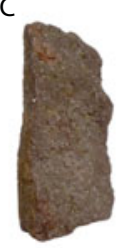

$\mathrm{H}$

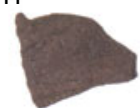

I

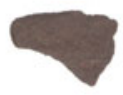

J

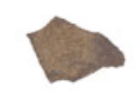

K

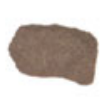

D

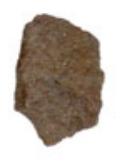

$\mathrm{L}$

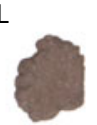

E

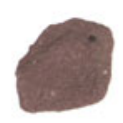

M

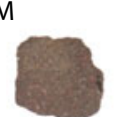

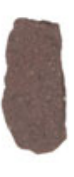

$\mathrm{L}$

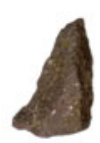

Figure 20. Examples of excavated small fragments of red ochre from Borologa 1 (photos: Steve Morton).

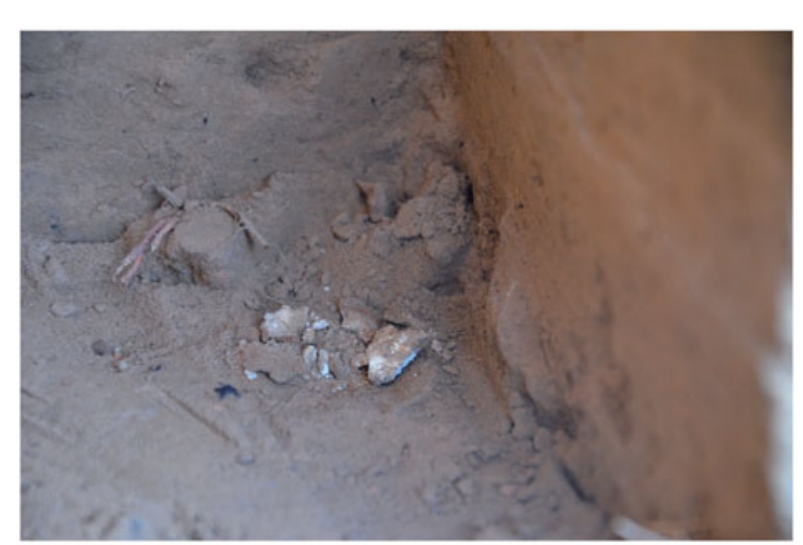

Figure 21. White pigment in XU17 of Square D7, immediately after exposure by sweep of the trowel (photo: Bruno David).

use of flat bedrock surfaces for the processing of ochre even closer to the painted ceiling. Either way, buried grindstones are not necessary for the recovery of paint by-products as evidence of painting events.

Last but not least, while the white background of the Wanjina panel at Borologa 1 began to be painted sometime between 2,080-1,160 cal BP, we can also now determine that it is during the past millennium that the most intensive painting and repainting of Wanjina motifs took place here. Given a periodic but unbroken chain of Wanjina artworks on rock over this time frame both at Borologa 1 and more broadly in the Kimberley, we can reasonably extend an approximation of key elements of the ethnographically known cosmological signification of Wanjina motifs back for many hundreds of years into history, with earlier, antecedent versions also apparent beyond c. 1,000 years ago. Today and in recent times, Wanjina spirit-beings express very particular local Aboriginal world views concerning the creative powers of ancestral beings and relating 

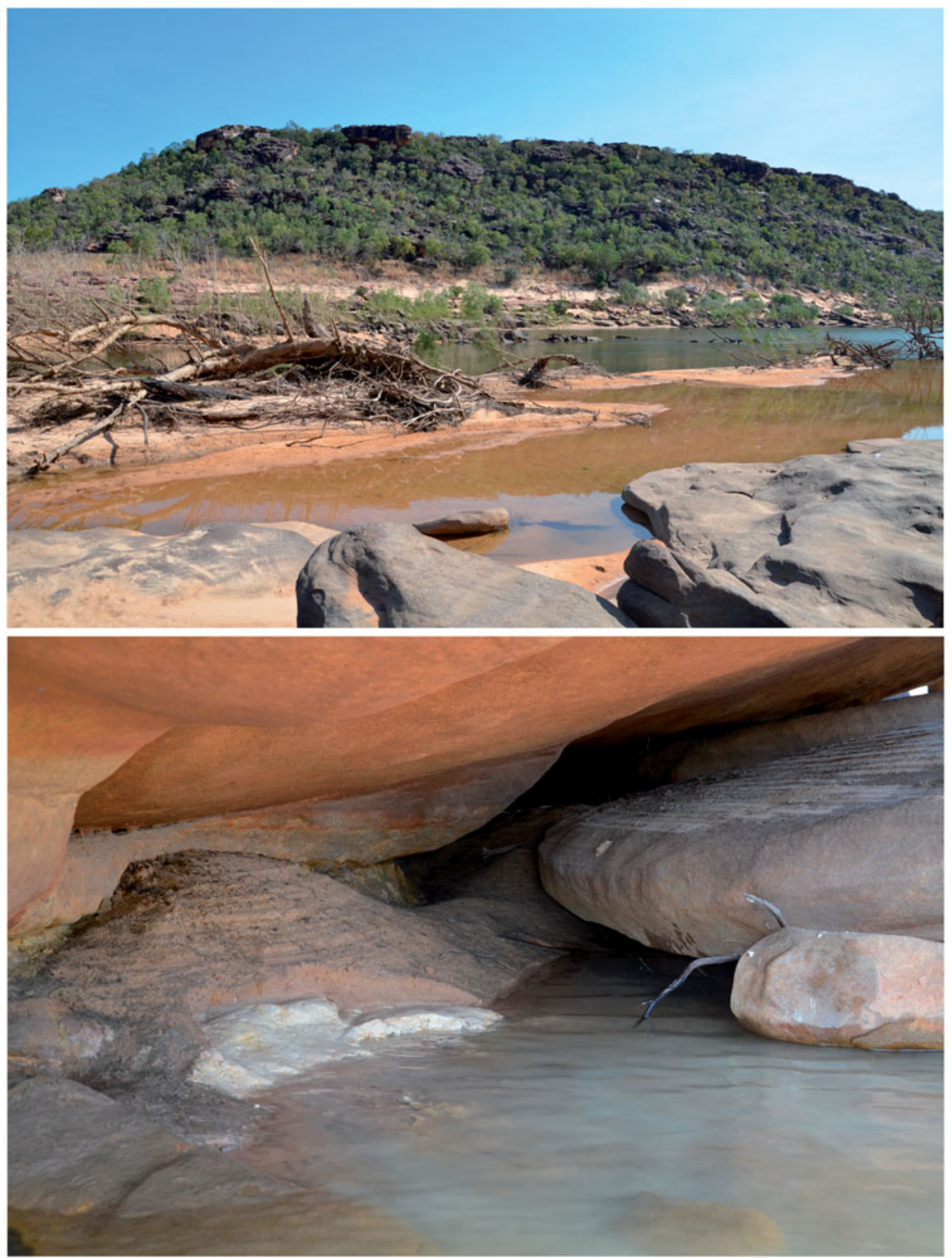

Figure 22. White pigment source on opposite side of Drysdale River to Borologa 1. Top: White pigment source under lowhanging rocks in foreground, with Borologa 1 on opposite side of river. Bottom: Close-up of white pigment source under low rock overhang in river bed. The white pigment layer was exposed by hand by sweeping aside the unconsolidated overlying layer of alluvial sand (photos: Bruno David).

people to ancestors, social (clan) affiliations, Law (as given by the ancestors at the beginning of time) and Country. We suggest that being able to track fundamental elements of Wanjina symbolism in the rock art back for 1000 years or more, signals long-lasting continuity in their associated cosmological associations. Yet such continuity of symbolic practice also needs to be considered in a longer sequence of dynamic change in Kimberley artistic practice, interregional relations, intensities of landscape engagement and wide-ranging geographical influences. These patterns and trends will be revealed better by a clearer understanding of the antiquity of each artwork's individual conventions and overall style. As we have demonstrated at Borologa 1, this will arguably require archaeological field methods aimed at connecting the buried archaeological evidence with the art on the exposed rock walls.

\section{Acknowledgements}

We thank Augustine Unghango and Balanggarra Traditional Owners for permission to work on their lands and partnership in doing so. For financial and 

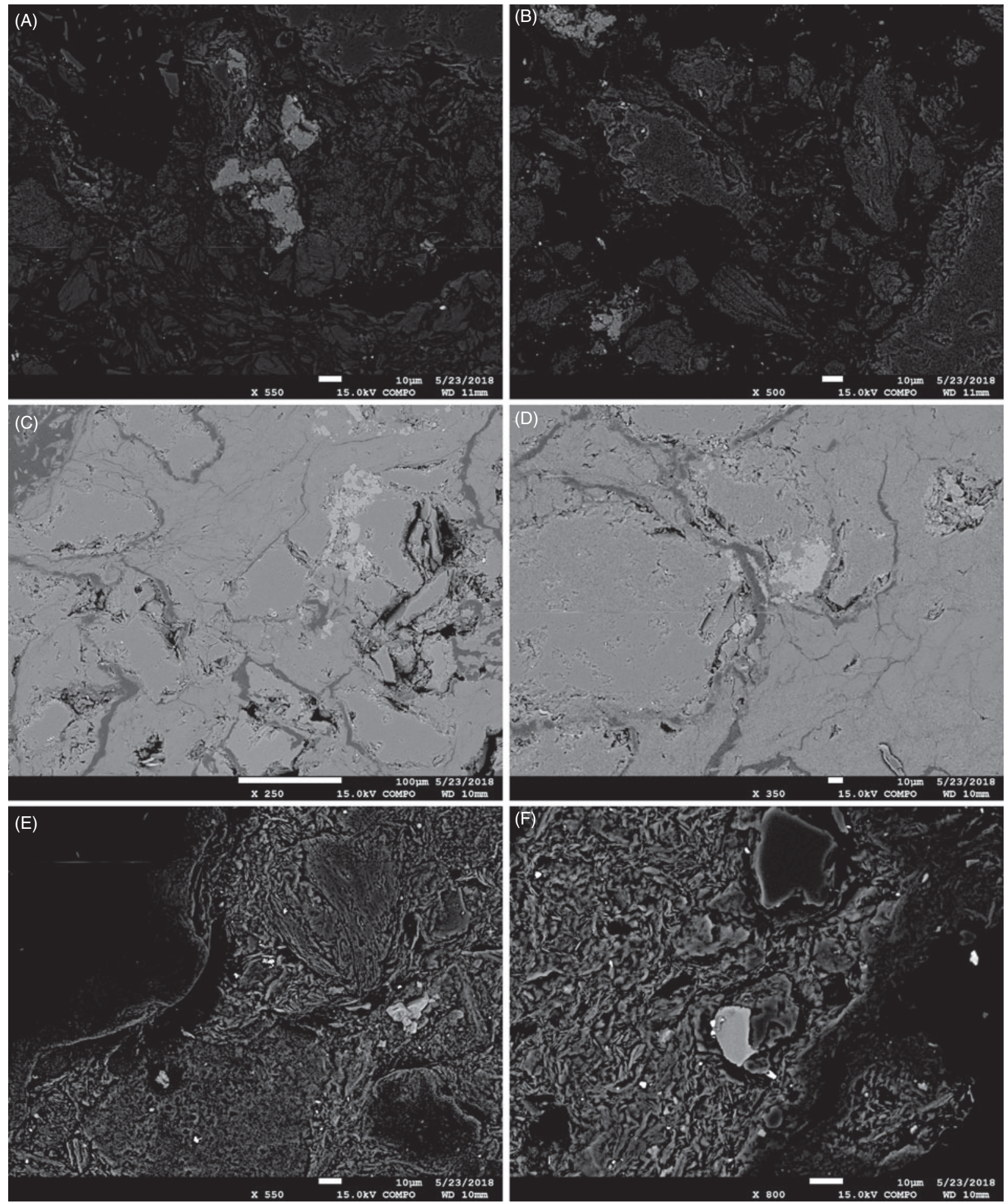

Figure 23. SEM backscattered micrograph of pigment samples. (A, B) From Location 1 in the Drysdale River Source (A: subsample 2; B: subsample 5). Typical Ti enrichment (lighter grains in the centre of A) surrounded by a typical clay (Si Al) matrix. The larger, slightly lighter matrix grains in the matrix contain more $\mathrm{Si}(\sim 18 \%)$ than the darker smaller grained sections ( $\sim 16 \%)$. Very small, bright grains are the Ti, Fe, Cu and Zr grains. (C, D) From Location 2 in the Drysdale River Source. Typical $\mathrm{Ti}$ enrichment (lighter grains in the top right of $\mathrm{C}$ and centre on $\mathrm{D}$ ) with typical clay (Si Al) matrix, the larger lighter matrix grains contain more $\mathrm{Si}(\sim 18 \%)$ than the darker smaller grained sections $(\sim 16 \%)$. Very small bright grains are the $\mathrm{Ti}, \mathrm{Fe}, \mathrm{Cu}$ and $\mathrm{Zr}$ grains. (E, F) From Square C5 XU22 (white) pigment fragment numbers 1 (E) and $3(F)$. The very small bright grains are rich in $\mathrm{Ti}, \mathrm{Fe}, \mathrm{Cu}$ and $\mathrm{Zr}$ (image: Jillian Huntley).

logistical support, we thank the Australian Research Council's 'Kimberley Visions: Rock Art Style Provinces of North Australia' project (LP150100490), the Monash Indigenous Studies Centre at Monash University, the University of Western Australia, Maria and Cecilia Myers, Susan Bradley, Kimberley Foundation Australia,
Dunkeld Pastoral Co. Pty. Ltd., the staff at Theda and Doongan Stations. We thank the excavation and rock art recording teams: Isaac Barney, Frank Boulden, Leigh Douglas, Adrian French, Paul Hartley, Brigid Hill, Lucas Karadada, Madeleine Kelly, Lorraine Lee, Robin Maher, William Maraltidj, Michael Morlumbin, 

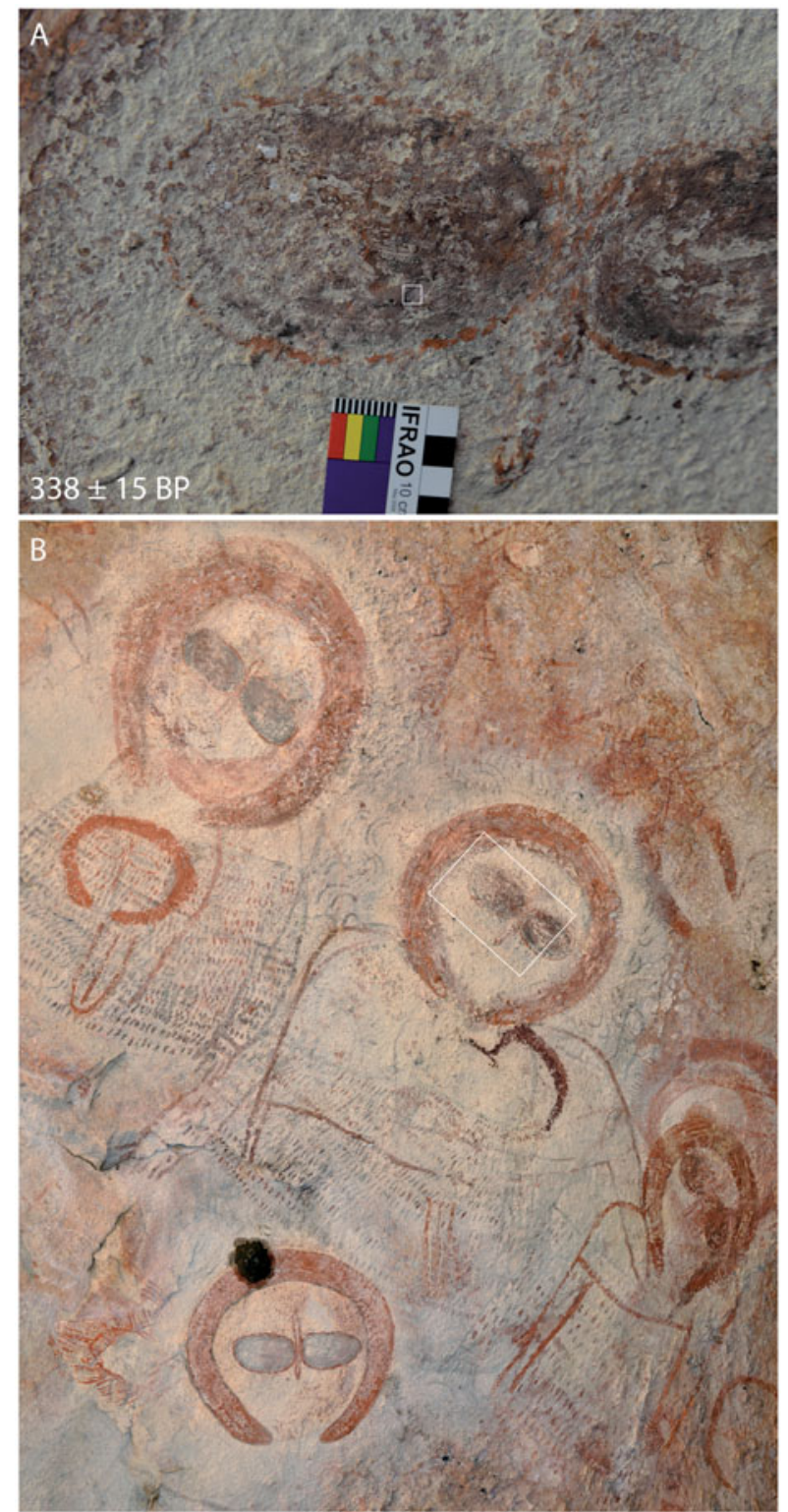

Figure 24. Sample of charcoal pigment collected for AMS radiocarbon dating from a painted black Wanjina eye, Borologa 1. A: Close-up of radiocarbon-dated area after sampling. B: Dated Wanjina in relation to neighbouring paintings (photos: Robert Gunn).

Ken Mulvaney, Nick Sundblom, Patrick Tataya, Gareth Unghango, Jeremy Unghango, Scott Unghango, Ian Waina, Rowan Waina and Uriah Waina. Thanks to Laura Jacobs for her assistance with pXRF and SEM analyses during her recently completed internship at Griffith University; Richard Cosgrove, Judith Field and Adelle Coster for starch analysis on the grindstones; and Liam Brady for comments on an earlier draft of the manuscript. Australian Research Council Laureate Grant FL160100123 supported JH's participation in this research; we thank Professor Paul Taçon. Scanning Electron Microscopy was undertaken at the Central Analytical Research Facility, Queensland University of Technology, and the particle size analyses and $\mathrm{pH}$ measurements were undertaken at Monash University, mostly by Ursula Pietrzak and Chris Urwin. Thanks to three anonymous referees for useful comments.

\section{Disclosure statement}

No potential conflict of interest was reported by the authors.

\section{Funding}

This study was funded by the Australian Research Council's 'Kimberley Visions: Rock Art Style Provinces of North Australia' project (LP150100490); Kimberley Foundation Australia; Dunkeld Pastoral Co. Pty. Ltd.

\section{ORCID}

Bruno David (D) http://orcid.org/0000-0002-8567-6135 Peter Veth (D) http://orcid.org/0000-0002-1717-6390 Jerome Mialanes (D) http://orcid.org/0000-0002-6790-7542

\section{References}

Akerman, K. 2016 Wanjina: notes on some iconic Ancestral Beings of the northern Kimberley. Carlisle: Hesperian Press.

Allen, M.S. and R. Wallace 2007 New evidence from the East Polynesian gateway: substantive and methodological results from Aitutaki, southern Cook Islands. Radiocarbon 49(3):1-17.

Aubert, M. 2012 A review of rock art dating in the Kimberley, Western Australia. Journal of Archaeological Science 39(3):573-577.

Balanggarra Aboriginal Corporation and Kimberley Land Council 2011 Balanggarra Healthy Country Plan 2012-2022 48. Retrieved 1 August 2018 from <http:// www.klc.org.au/docs/default-source/Ranger-Fact-Sheets/ balanggarra-healthy-country-plan-2012-2022?sfvrsn=4>

Blundell, V., K. Doohan, D. Vachon, M. Allbrook, M.A. Jebb and J. Bornman 2017. Barddabardda Wodjenangorddee: we're telling all of you. Fremantle: Fremantle Press.

Bronk Ramsey, C. 1995 Radiocarbon calibration and analysis of stratigraphy: the OxCal program. Radiocarbon 37(02):425-430.

Bronk Ramsey, C. 2009 Bayesian analysis of radiocarbon dates. Radiocarbon 51(1):337-360.

Bronk Ramsey, C. 2018 OxCal Program v4.3. Radiocarbon accelerator unit. Oxford: University of Oxford.

Bronk Ramsey, C., M. Dee, S. Lee, T. Nakagawa and R. Staff 2010 Developments in the calibration and modelling of radiocarbon dates. Radiocarbon 52(03):953-961.

Brumm, A., M.C. Langley, M.W. Moore, B. Hakim, M. Ramli, I. Sumantri, B. Burhan, A.M. Saiful, L. Siagian, R.S. Suryatman, A. A. Jusdi, A.P. Mubarak, H. Hasliana, A.A. Oktaviana, S. Adhityatama, G.D. van den Bergh, M. Aubert, J. Zhao, J. Huntley, B. Li, R.G. Roberts, E.W. Saptomo, Y. Perston and R. Grün 2017 Early human symbolic behavior in the Late Pleistocene of Wallacea. Proceedings of the National Academy of Sciences 114(16): 4105-4110.

Capell, A. 1972 Cave painting myths: northern Kimberley. Oceania Linguistic Monographs 18. Sydney: University of Sydney.

Chalmin, E. and J. Huntley 2017 Characterizing rock art pigments. In B. David and I. J. McNiven (eds), The Oxford handbook of the archaeology and anthropology of rock art. Oxford: Oxford University Press. 
Chippindale, C. and P. S. C. Taçon (eds) 1998 The archaeology of rock-art. Cambridge: Cambridge University Press

Clarke, J. 1976 Two Aboriginal rock art pigments from Western Australia: their properties, use and durability. Studies in Conservation 21:134-142.

Crawford, I.M. 1968 The art of the Wandjina: Aboriginal cave paintings in Kimberley, Western Australia. Melbourne: Oxford University Press.

David, B., J.-J. Delannoy, R. Gunn, E. Chalmin, G. Castets, F. Petchey, K. Aplin, M. O'Farrell, I. Moffat, J. Mialanes and J.-M. Geneste 2017 Dating painted Panel E1 at Nawarla Gabarnmang, central-western Arnhem Land plateau. In B. David, P. S. C. Taçon, J.-J. Delannoy and J.-M. Geneste (eds), The archaeology of rock art in western Arnhem Land, Australia, pp. 245-302. Terra Australis 47. Canberra: ANU Press.

Donaldson, M. 2012 Kimberley rock art 2: north Kimberley. Mt Lawley: Wildrocks Publications.

Elkin, A.P. 1930 Rock paintings in north-west Australia. Oceania 1(3):257-279.

Ford, B., I. MacLeod and P. Haydock 1994 Rock art pigments from the Kimberley region of Western Australia: identification of the minerals and conversion mechanisms. Studies in Conservation 39(1):57-69.

Green, H., A. Gleadow, D. Finch, J. Hergt and S. Ouzman 2017 Mineral deposition systems at rock art sites, Kimberley, northern Australia - field observations. Journal of Archaeological Science: Reports 14:340-352.

Hughes, P.J. 1976 Inferred rates of weathering in sandstone shelters in southern NSW: some implications for the preservation of rock art. In C. Pearsons and G. L. Pretty (eds), Proceedings of the 1st national seminar on the conservation of cultural material. Perth, 1973. Sydney: Institute for the Conservation of Cultural Materials.

Huntley, J. 2015 Looking up and looking down: pigment chemistry as a chronological marker in the Sydney Basin rock art assemblage, Australia. Rock Art Research 32(2):131-145.

Huntley, J., M. Aubert, J. Ross, H.E.A. Brand and M.J. Morwood 2015 One colour (at least) two minerals: a study of mulberry rock art pigment and a mulberry pigment 'quarry' from the Kimberley, northern Australia. Archaeometry 57(1):77-99.

Huntley, J., H.E.A. Brand, M. Aubert and M.J. Morwood 2014 The first Australian Synchrotron powder diffraction analysis of pigment from a Wandjina motif in the Kimberley, Western Australia. Australian Archaeology 78(1):33-38.

Johnson, J. 2014 Accurate measurements of low Z elements in sediments and archaeological ceramics using portable X-ray fluorescence (PXRF). Journal of Archaeological Method and Theory 21(3):563-588.

Lommel, A. 1952 The Unambal: a tribe in northwest Australia. Carnarvon Gorge: Takarakka Nowan Kas Publications. (1997 translation by I. Campbell).

McNiven, I.J., L.M. Brady and A.J. Barham 2009 Kabadal Kula and the antiquity of Torres Strait rock art. Australian Archaeology 69:29-40.

Morwood, M.J., G.L. Walsh and A.L. Watchman 2010 AMS radiocarbon ages for beeswax and charcoal pigments in north Kimberley rock art. Rock Art Research 27(1):3-8.

Mowaljarlai, D., and J. Malnic 1993 Yorro Yorro: spirit of the Kimberley. Broome: Magabala Books.

O'Connor, S., A. Barham and D. Woolagoodja 2008 Painting and repainting in the West Kimberley. Australian Aboriginal Studies 1:22-38.
Ouzman, S., P. Veth, C. Myers, P. Heaney and K. Kenneally 2017 Plants before animals? Aboriginal rock art as evidence of ecoscaping in Australia's Kimberley. In B. David and I. J. McNiven (eds), The Oxford handbook of the archaeology and anthropology of rock art. Oxford: Oxford University Press. doi:10.1093/oxfordhb/ 9780190607357.013.31

Reimer, P.J., E. Bard, A. Bayliss, J.W. Beck, P.G. Blackwell, C. Bronk Ramsey, C.E. Buck, H. Cheng, R.L. Edwards, M. Friedrich, P.M. Grootes, T.P. Guilderson, H. Haflidason, I. Hajdas, C. Hatté, T.J. Heaton, D.L. Hoffmann, A.G. Hogg, K.A. Hughen, K.F. Kaiser, B. Kromer, S.W. Manning, M. Niu, R.W. Reimer, D.A. Richards, E.M. Scott, J.R. Southon, R.A. Staff, C.S.M. Turney and J. van der Plicht 2013 IntCal13 and Marine13 radiocarbon age calibration curves, 0-50,000 years cal BP. Radiocarbon 55(04):1869-1887.

Roberts, R.,. G. Walsh, A. Murray, J. Olley, R. Jones, M. Morwood, C. Tuniz, E. Lawson, M. Macphail, D. Bowdery and I. Naumann 1997 Luminescence dating of rock art and past environments using mud-wasp nests in northern Australia. Nature 387(6634):696-699.

Ross, J., K. Westaway, M. Travers, M.J. Morwood and J. Hayward 2016 Into the past: a step towards a robust Kimberley rock art chronology. PLoS ONE 11(8):1-33.

Schiffer, M.B. 1987 Formation processes of the archaeological record. Albuquerque: University of New Mexico Press.

Schulz, A.S. 1956 North-west Australian rock paintings. Memoirs of the National Museum of Victoria 20:7-43.

Thomas, A.M. 1998 Spirit of the serpent: an ethnographic and scientific analysis of the white pigments used in Wandjina rock art, Kimberleys, Western Australia. Unpublished BA(Hons) thesis, Department of Archaeology and Paleoanthropology, University of New England, Armidale.

Veth, P., C. Myers, P. Heaney, and S. Ouzman 2018 Plants before farming: the deep history of plant-use and representation in the rock art of Australia's Kimberley region. Quaternary International 489:26-45.

Walsh, G.L. 2000 Bradshaw art of the Kimberley. Toowong: Takarakka Nowan Kas Publications.

Ward, I., A.L. Watchman, N. Cole and M.J. Morwood 2001 Identification of minerals in pigments from Aboriginal art in the Laura and Kimberley regions, Australia. Rock Art Research 18(1):15-23.

Watchman, A.L. 1987 Preliminary determinations of the age and composition on mineral salts on rock art surfaces in the Kakadu National Park. In W. R. Ambrose and J. M. J. Mummery (eds), Archaeometry: further Australasian studies, pp. 36-42. Canberra: Australian National University.

Watchman, A.L. 1997 Kimberley and Hann River paint and accretion compositions. Unpublished report prepared for the Australian Institute of Aboriginal and Torres Strait Islander Studies, Canberra.

Watchman, A.L. 2000 Micro-excavation and laser extraction methods for dating carbon in silica skins and oxalate crusts. In G. Ward and C. Tuniz (eds), Advances in dating Australian rock markings: papers from the first Australian rock picture dating workshop, pp. 35-39. Occasional AURA Publication 10. Melbourne: Australian Rock Art Research Association.

Watchman, A.L., B. David, I.J. McNiven and J. Flood 2000 Micro-archaeology of engraved and painted rock surface crusts at Yiwarlarlay (the Lightning Brothers site), Northern Territory, Australia. Journal of Archaeological Science 27(4):315-325. 
Welch, D. 1993 The early rock art of the Kimberley, Australia: developing a chronology. In J. Steinberg, A. Watchman, P. Faulstich and P. S. C. Taçon (eds), Time and space: dating and spatial considerations in rock-art research, pp. 13-21. Occasional AURA Publication 8. Melbourne: Australian Rock Art Research Association.

Welch, D. 2015 Aboriginal paintings of Drysdale River National Park, Kimberley, Western Australia. Coolalinga: David M. Welch.

\section{Appendix A: Geochemical Analyses of Excavated and Source Pigments}

A powerful application of portable X-Ray Fluorescence spectrometry (pXRF) in rock art research has been to identify qualitatively the composition of mineral pigments based on their major chemical constituents. The procedure involves positing at least two chemically distinctive alternatives for mineral pigments of the same colour. Following this premise, several studies have distinguished between chemically discrete pigment sources (Brumm et al. 2017; Chalmin and Huntley 2017; Huntley 2015).

pXRF analyses were conducted on excavated pigments from Borologa and from the nearby source (see text for details of individual samples) using a Bruker Tracer $5 \mathrm{i}$ pXRF equipped with an $8 \mu \mathrm{m}$ Beryllium, rhodium tube and $20 \mathrm{~mm}^{2}$ silicon drift detector (resolution of $<140 \mathrm{eV}$ at 250,000 counts per second on the Mn K $\alpha$ line). Assays were collected over 90 live seconds using an $8 \mathrm{~mm}$ collimator at $15 \mathrm{kV}$ and $39 \mu \mathrm{A}$ under vacuum $(<20 \mathrm{psi})$ to remove air from the beam path, with the addition of a $25 \mu \mathrm{m}$ Ti filter (as measurement of $\mathrm{Cl}$ and $\mathrm{S}$ was desirable). Relative element abundances were calculated using Artax (V8) software following the manual interrogation of each spectrum (Table 8). Certified reference materials were included in analytic program to monitor instrument stability (Johnson 2014). Almost all the excavated specimens analysed were smaller than the pXRF instrument aperture $(<5 \mathrm{~mm}$ diameter $)$, which has resulted in lower fluorescent yields for specimens and hence lower element abundances. Field emission SEM was undertaken on a Joel 7100 JSM. Energy Dispersive Spectrometry (EDS) of relative element abundances measured in spot, area and element mapping modes using an Oxford X-Max 80 probe and Aztec software. Two subsamples from different locations of a white pigment source located across the river from Borologa 1, and one example of white pigment from the excavation (Square C5 XU22) were embedded in epoxy resin and exposed in cross-section prior to gold coating for investigation.

Across the Kimberley where Wanjina paintings have previously been characterised, white paints have been found to be predominantly clay (kaolinite, sometimes including micas such as muscovite) or huntite minerals (Chalmin and Huntley 2017; Clarke 1976; Huntley et al. 2014). Chemically, clays are principally silicon and aluminium, around $20 \%$ by weight each in kaolinite $\left(\mathrm{Al}_{2} \mathrm{Si}_{2} \mathrm{O}_{5}(\mathrm{OH})_{4}\right)$ and muscovite $\left(\mathrm{KAl}_{2}\left(\mathrm{AlSi}_{3} \mathrm{O}_{10}\right)(\mathrm{FOH})_{2}\right)$. In contrast, huntite is composed of around $11 \%$ calcium and $20 \%$ magnesium by weight $\left(\mathrm{CaMg}_{3}\left(\mathrm{CO}_{3}\right)_{4}\right)$. Differentiating these minerals by pXRF is therefore straightforward - clays display large $\mathrm{Al}$ and $\mathrm{Si}$ peaks (including $\mathrm{K}$ in micas), whereas huntite has large $\mathrm{Ca}$ peaks and $\mathrm{Mg}$.

pXRF analysis of white pigment specimens recovered from the Borologa 1 excavations returned spectra dominated by aluminium and silicon, indicating clay constituents for these pigments (Table 8). Calcium and iron are consistently present in low to moderate abundance. Titanium was persistently measured (above the peak generated by the instrument filter). pXRF readings indicate the absence of weathering products such as geological salts (sulphur and chlorine each having persistently low readings). Elevated phosphorous abundances were found in the small mass of white pigment from Square D7 XU17 and the red fragment with white paint residue from Square D7 XU18 (both from Pigment Horizon II), a tantalising possibility that organic binding media may have been used in composite paint recipes, although this requires further investigation.

SEM analyses of two white pigments from Square C5 XU22 (Pigment Horizon I) and four samples from two locations in the white pigment source showed they are all predominantly clay constituents (high relative abundances of $\mathrm{Al}$ and $\mathrm{Si}, \sim 18 \%$ and $13 \%$ by weight respectively). EDS analyses also revealed a consistently low presence of magnesium ( 0.2 to $0.5 \%$ by weight, with a single grain of $6.5 \%$ by weight noted). Despite persistent minor $\mathrm{Mg}$, calcium was rarely observed with SEM. Low potassium abundances are also common (3.5-8.0\% by weight). Both the excavated and source white pigments contain elevated titanium-enriched zones consistent with the elevated titanium levels observed in some of the EDS spectra ( $\sim 25-50 \%$ by weight; the lighter sections shown in the SEM backscattered micrographs of Figure 23 are titanium-rich). Small grains, bright under the backscatter detector, were shown with EDS to contain one dominant metal, either $\mathrm{Ti}, \mathrm{Fe}, \mathrm{Cu}$ or $\mathrm{Zn}$ (the sub-micron white grains in Figure 23). Only one isolated feature containing Ca $(\sim 17 \%$ by weight) was observed in the sample from the second location in the white pigment source. The near-absence of $\mathrm{Ca}$, and occurrence of $\mathrm{Mg}$ as a persistent minor chemical component associated with $\mathrm{Si}$ and $\mathrm{Al}$ (not $\mathrm{Ca}$ ), confirmed the very low $\mathrm{Ca}$ measured by pXRF and determined that the white pigments cannot be huntite.

Importantly, white pigment sources (Clarke 1976; Thomas 1998) and white pigment known to have been used to paint Wanjina motifs in the Kimberley have previously been identified as mixed minerals (Ford et al. 1994; Huntley et al. 2014; Ward et al. 2001; Watchman 1997). The variations in clay-rich white pigments observed in the excavated samples from Borologa 1 and nearby source are therefore consistent with these previous characterisations. The presence of $\mathrm{P}$ and $\mathrm{Mg}$ detected by SEM in the excavated Borologa 1 and nearby source samples likely reflects minor mica mineral phases such as phlogopite $\left(\mathrm{KMg}_{3} \mathrm{AlSi}_{3} \mathrm{O}_{10} \mathrm{~F}(\mathrm{OH})\right)$, which had previously been identified in Kimberley rock art in the Lower Mitchell Falls area c. $135 \mathrm{~km}$ west-northwest of Borologa 1 (Huntley et al. 2015).

Internal variation was noted in the morphology and composition of the Drysdale River white pigment source locations near Borologa 1. Of the subsamples from two adjacent locations along the exposed clay bed, samples from the second have higher silicon content than the first source location and the excavated archaeological specimens. The general morphology of the pigment from the second source location is more amorphous, likely related to silica enrichment (Figures 23C, 23D).

Previous mineralogical analyses at other sites in the Kimberley identified minor phases of iron-rich minerals in white Wanjina paint flakes, though this has been 
presumed to be due to weathering processes on the art panel surfaces associated with their tropical environment (Ford et al. 1994; Huntley et al. 2014). Here we have shown that $\mathrm{Fe}$ is common in both excavated white pigments at Borologa 1 and in the nearby white clay source, and that the excavated white pigment was probably local (Table 8).
The predominance of $\mathrm{Al}$ and $\mathrm{Si}$ was also measured in relative abundances via pXRF for the excavated red ochre fragments (Table 8). Combined with the absence of $\mathrm{Ca}$, again we interpret this as evidence of a clay matrix for the red ochres, indicating a similar local geomorphic environment for its source(s) (Huntley 2015). 


\section{Dating painting events through by-products of ochre processing: Borologa 1 Rockshelter, Kimberley, Australia}

Bruno David, Jean-Jacques Delannoy, Fiona Petchey, Robert Gunn, Jillian Huntley, Peter Veth, Kim Genuite, Robert J. Skelly, Jerome Mialanes, Sam Harper, Sven Ouzman, Balanggarra Aboriginal Corporation, Pauline Heaney \& Vanessa Wong

To cite this article: Bruno David, Jean-Jacques Delannoy, Fiona Petchey, Robert Gunn, Jillian Huntley, Peter Veth, Kim Genuite, Robert J. Skelly, Jerome Mialanes, Sam Harper, Sven Ouzman, Balanggarra Aboriginal Corporation, Pauline Heaney \& Vanessa Wong (2019): Dating painting events through by-products of ochre processing: Borologa 1 Rockshelter, Kimberley, Australia, Australian Archaeology, DOI: 10.1080/03122417.2019.1603263

To link to this article: https://doi.org/10.1080/03122417.2019.1603263

Published online: 17 May 2019.

Submit your article to this journal

View Crossmark data \lceil 